\title{
Hominis historia naturalis - \\ Georg Forsters Vorlesung von 1786/87 im Zusammenhang seiner Anthropologie
}

LUDWIG UHLIG 
Vorgestellt von Günter Arnold in der Sitzung vom 23. Oktober 2009 
Das Corpus der Werke Georg Forsters wird von dem zuletzt erschienenen Band der Berliner Akademieausgabe beträchtlich erweitert um einen Bereich, der bisher nur selten in Rechnung gezogen wurde: das umfangreiche naturhistorische Werk des Gelehrten, das ein lange vermißtes Gegengewicht gegen seine bekannteren Zeitschriftenessays bildet. ${ }^{1}$ Diese, bereits zu Forsters Lebzeiten publiziert und seither in jeder Hinsicht leicht zugänglich, bestimmten auf höchst einseitige Weise das immer noch verbreitete Bild ihres Verfassers, der selbst in ihnen nur seine „kleinen Erholungen an eigner Composition“ sah. ${ }^{2}$ Eine wissenschaftliche Verbindlichkeit, die ihnen oft zugeschrieben wird, kommt ihnen nur in beschränktem Maße zu.

Einer angemessenen Rezeption der neu gewonnenen Quellen steht allerdings ein Hindernis im Wege, das, so trivial es zu sein scheint, doch eine kaum auflösbare kognitive Dissonanz hervorruft und damit die meisten neuerlichen Bemühungen um Forsters Arbeiten zur Naturgeschichte, zumal zur Anthropologie, der dilettantischen Unzulänglichkeit

1 Georg Forsters Werke. Sämtliche Schriften, Tagebücher, Briefe, hrsg. v. d. Berlin-Brandenburgischen Akad. d. Wissensch. Bd 6, Teil 1 und 2. Berlin 2003; Klaus-Georg Popp hat diese (wie schon frühere) Texte mit mustergültiger Handschriftenkenntnis und Sachkompetenz herausgegeben, und es ist zu hoffen, daß bald seine Erläuterungen im dritten Teilband folgen werden. Diese Gesamtausgabe Forsters, begonnen unter der Ägide der Deutschen Akademie der Wissenschaften zu Berlin, später der Akademie der Wissenschaften der DDR, wird weiterhin unter der Sigle AA zitiert, mit römischen Ziffern für die Bände und arabischen Ziffern für die Seitenzahlen. Ich danke Klaus-Georg Popp für hilfreiche Hinweise und Korrekturen sowie dafür, daß er mir einige der hier behandelten Texte bereits vor ihrer Publikation mitgeteilt hat. Eine knappe Zusammenfassung der hier vorgelegten Studie erschien bereits unter dem Titel: Hominis historia naturalis. Georg Forsters Vorlesung von 1786/87 im Zusammenhang seiner Anthropologie. Zwanzig Thesen. In: Philippia. Abhandlungen und Berichte aus dem Naturkundemuseum im Ottoneum zu Kassel. 13/4. 2008. S. 335-338. Mittlerweile sind zwei weitere Arbeiten verwandter Thematik erschienen: Ludwig Uhlig: Erkenntnisfortschritt und Traditionsbindung in Georg Forsters naturwissenschaftlichem Werk. In: Georg-Forster-Studien, hrsg. im Auftr. d. Georg-Forster-Gesellschaft v. Stefan Greif u. Michael Ewert. Kassel: Kassel Univ. Pr. Bd. 15. (2010). S. 55-75; sowie: ders.: Die Südseevölker und Georg Forsters Rassenbegriff. Ebenda. S. 137-172.

2 AA XV 356; vgl. Ludwig Uhlig: Mitbürger unserer Gelehrtenrepublik. Georg Forsters Beiträge $\mathrm{zu}$ den zeitgenössischen deutschen Zeitschriften. In: Zeitschrift für deutsche Philologie. 121, 2002. S. 161-186, bes. S. 162, sowie ders.: Georg Forster. Lebensabenteuer eines gelehrten Weltbürgers (1754-1794). (Göttingen): Vandenhoeck \& Ruprecht (2004) [weiterhin zitiert als: Uhlig 2004]. S. 13. 
überführt: die verbreitete Unkenntnis der lateinischen Sprache verschließt den Zugang zu ihnen so hermetisch, daß sogar ihre Existenz geleugnet werden kann. Nach einer vorgeblichen „Sichtung“ von Forsters Schriften zur Naturkunde wurde unlängst behauptet: „,eine medizinische Anthropologie, eine Anatomie und Physiologie des menschlichen Körpers sucht man bei ihm also vergeblich". ${ }^{3}$ Das Gegenteil ist der Fall, wie die hier vorgelegte Studie zeigt. Diese ist ein erster Ansatz, das naturwissenschaftliche Werk Forsters mit strenger Konzentration auf die vorliegenden Zeugnisse und ihre nachweisbaren Bezüge zu erschließen. Da hier ausgedehnte Bereiche noch unerforscht sind und unentbehrliche Aufschlüsse nur aus Zusammenhängen zwischen verschiedenen getrennt überlieferten Schriften zu gewinnen sind, ist es unvermeidlich, gelegentlich mit weiter ausholenden Exkursen vom eigentlichen Gegenstand der Untersuchung abzuschweifen und diesen so in seinen Kontext einzubinden. Um heutigen Lesern die Quellen so nahe wie möglich zu bringen, übersetze ich lateinische Texte, darunter einige größeren Umfangs, ins Deutsche.

Als Lehrling und Gehilfe seines Vaters von klein auf zum Gelehrten in der Tradition der Botanik und Natursystematik Linnés erzogen, hatte Forster sich das Lateinische schon früh angeeignet und benutzte es seit der Weltreise in seinen Pflanzenbeschreibungen. ${ }^{4}$ Vor die Wahl gestellt,

3 Tanja van Hoorn: Das anthropologische Feld der Aufklärung. Ein heuristisches Modell und ein exemplarischer Situierungsversuch (Georg Forster). In: Natur Mensch - Kultur. Georg Forster im Wissenschaftsfeld seiner Zeit. Hrsg. v. Jörn Garber u. Tanja van Hoorn. (Hannover-Laatzen:) Wehrhahn Verl. (2006). S. 125-141, Zitat S. 138. Ein sprachlich bedingtes Unverständnis der Texte und ihrer Zusammenhänge verraten auch Rezensionen des betreffenden Bandes der Akademieausgabe, die wortreich ablenkend vor genauen Angaben zu seinen lateinischen Bestandteilen ausweichen und damit ein völlig verzerrtes Bild zeichnen: Horst Dippel (Georg Forsters Schriften zur Naturkunde. In: GeorgForster-Studien. Hrsg. im Auftr. d. Georg-Forster-Gesellschaft v. Horst Dippel u. Helmut Scheuer. IX. Kassel: Univ. Press 2004. S. 263-268, Zitat S. 265) bemängelt das Ausbleiben des Kommentars, der dem noch ausstehenden dritten Teilband vorbehalten ist, aber damit allein kann er unmöglich rechtfertigen, daß ihm ,vieles unklar und unerschlossen“ bleibt; die Einleitung zu einem späten Fragment verdankt es offenbar nur ihrer deutschen Sprachform, daß Dippel sie als einzigen Text vor allen anderen, substanzielleren, hervorhebt. Dies tut auch Petra Feuerstein-Herz (NTM. Zeitschrift für Geschichte der Wissenschaften, Technik und Medizin. Basel: Birkhäuser Verl. N. S. 14, 2006. S. 189-191) und verschleiert im übrigen ihre Unkenntnis, indem sie einige periphere Einzelheiten anführt, die sie offensichtlich andernorts vorgefunden hat (vgl. Uhlig 2004 S. 181, 198-200).

4 Vgl. Uhlig 2004 S. 11, 26, 30, 35, 58, 76, 199-201. 
in Wilna polnisch oder lateinisch zu dozieren, ${ }^{5}$ entschied er sich selbstverständlich für die internationale Gelehrtensprache, obwohl ihm die Ausarbeitung längerer Vorträge zunächst „horribel schwer“ fiel. ${ }^{6}$ Aber seine polyglotte Sprachfertigkeit bewährte sich auch hier, und indem er sich durch Lektüre der Klassiker schulte, erwarb er Sicherheit und Gewandtheit in Idiomatik und Periodenbau und erreichte Höhepunkte kraftvoller Prägnanz. Noch 1793, in seinem vermutlich letzten Ansatz zu einer naturwissenschaftlichen Arbeit, bezeichnete Forster den Gebrauch des Lateinischen als unumgänglich für ein Kompendium der Naturgeschichte zum Schulgebrauch. ${ }^{7}$

Bei der Vorbereitung seiner Wilnaer Vorlesungen suchte er im stillen seine Fachkenntnis zu erweitern und Lücken aufzufüllen, die sein unmethodischer Bildungsgang gelassen hatte. Schon mit der mineralogischen Vorlesung im Winter 1785/86 glaubte er, „,docendo viel gelernt“ zu haben, und er hoffte dies ebenso in der Zoologie und der Botanik zu erreichen. ${ }^{8}$ So stellen diese Vorlesungen auch keine völlig originellen Leistungen dar, da Forster hier, der üblichen Praxis des akademischen Lehrvortrags entsprechend, ausgiebig auf andere Autoren zurückgreift. Ähnlich bestand bereits seine Kasseler Vorlesung Ein Blick in das Ganze der Natur großenteils aus Übersetzungen und Paraphrasen von zwei Kapiteln aus Buffons Histoire naturelle, ${ }^{9}$ und sein Vortrag De hominis in omni climate vivendi facultate vom 8 . Dezember 1785 macht sich zahlreiche von Eberhard August Wilhelm Zimmermann aufgefuihrte Beispiele zunutze. $^{10}$

5 Vgl. den Brief von Jan Baptysta Czempińsky an Forster vom 28. Januar 1784, AA XVIII 128, sowie Uhlig 2004 S. 155, 157.

6 Vgl. AA XIV 252, 260, 264.

7 „Libellum latine conscribendum esse suadebant nomina rerum naturalium generica et specifica, termini artis, systematis membra et definitiones, quae omnia latinis vocabulis propter linguae concinnitatem designari solent. Neque hoc in prima historiae naturalis institutione levioris esse momenti arbitratus sum, effecturum me scilicet interpretatione latini compendii, ut auditores Linnaeum intelligant, cuius scripta et nomina systematica corporibus naturalibus imposita, per universam fere Europam civitate donata, etiam in cathedris jure meritòque principatum obtinuerunt." Rudimentum Naturalis Historiae. in usum scholarum congessit Georgius Forster, M. D. Moguntiae, 1793. Praefatio. AA VI 1769.

8 AA XIV 487, vgl. auch AA XIV 493, 501.

9 Vgl. Ludwig Uhlig: Georg Forster. Einheit und Mannigfaltigkeit in seiner geistigen Welt. Tübingen: Niemeyer 1965 [weiterhin zitiert als: Uhlig 1965]. S. 48-50, 267f., sowie Uhlig 2004 S. $127 f$.

10 AA VI 1045-1060, vgl. E[berhard] A[ugust] W[ilhelm] Zimmermann: Ueber die Verbreitung und Ausartung des Menschengeschlechts. Leipzig: Weygand 
Auch in der zoologischen Vorlesung vom Jahr 1786/87, um die es uns hier geht, zitiert Forster weithin wortwörtlich namentlich genannte Quellen; an wichtigen Punkten allerdings trennt er sich von ihnen und verfolgt eigene Wege. Damit ordnet er sich in den wissenschaftlichen Diskurs seiner Zeit ein und markiert zugleich seinen wohlbedachten eigenen Standort darin. Dieser wird noch klarer sichtbar, wenn die Beziehungen aufgedeckt werden, die den Text mit Forsters früheren und späteren Werken und dem zeitgenössischen Kontext verbinden. Der Mensch nimmt in dieser Vorlesung eine hervorragende Stellung ein, so daß hier Forsters ausführlichste und gründlichste Arbeit zur Anthropologie vorliegt. ${ }^{11}$ Der betreffende Teil des Kollegs kam im Dezember 1786 zum Vortrag. ${ }^{12}$ In der Chronologie der Werke Forsters folgt er also einerseits den beiden botanischen Arbeiten De plantis esculentis insularum oceani australis und Florulae insularum australium prodromus vom Frühjahr sowie den Aufsätzen Noch etwas über die Menschenraßen vom Juli und Neuholland und die brittische Colonie in Botany-Bay vom November 1786, während er andererseits dem Ende März 1787 abgeschlossenen Essay Cook der Entdecker vorausgeht, den Forster seiner Übersetzung der Beschreibung von Cooks letzter Reise beigab. Dieser Text allein liefert die Rechtfertigung dafür, daß Forster wenig später in der Vorrede zur Sammlung seiner frühen Schriften behaupten konnte:

Die Naturwissenschaft im weitesten Verstande, und insbesondere die Anthropologie war bisher meine Beschäftigung. Was ich seit meiner Weltumschiffung geschrieben habe, steht damit großentheils in enger Beziehung. ${ }^{13}$

Die Vorlesung fand ihren Niederschlag in drei überlieferten Manuskripten: Eine Eröffnungsansprache, Adlocutio, ${ }^{14}$ begrüßt die Studenten mit einem Rückblick auf Forsters Vorlesungen der vergangenen Jahre, wobei auch die Hindernisse zur Sprache kommen, die eine vollständige Ausführung seiner Pläne vereitelten: seine schwere Krankheit im Sommer 1785 und der Mangel an Hilfsmitteln zu anschaulichen Demonstra-

1778. S. 31-53. Der Hinweis auf Zimmermann als Quelle der Vorlesung Forsters ergänzt und korrigiert die betreffenden Ausfuhrungen in Uhlig 2004 S. $198 f$.

11 Vgl. Uhlig 2004 S. 180-182. Was dort allgemein über Forsters Wilnaer Vorlesungen gesagt wird, soll der hier vorgelegte Beitrag vertiefen und stellenweise korrigieren.

12 Vgl. die Datumsangaben in AA VI 1670 und 1712.

13 Kleine Schriften. Ein Beytrag zur Völker- und Länderkunde, Naturgeschichte und Philosophie des Lebens, gesammlet von Georg Forster. Erster Theil. Leipzig: Kummer 1789. Vorrede Bl. 3 v; abgedruckt in: AA V 345.

14 AA VI 1061-1064. 
tionen und Experimenten. Eine methodische Vorschau verspricht, zum besseren Verständnis der „Lebensfunktionen, aus denen sozusagen die Tierheit selbst besteht", der systematischen Übersicht über die Tierwelt eine kurzgefaßte Lehre vom inneren Bau der Tiere vorauszuschicken. ${ }^{15}$ Das zweite Manuskript, ein Kompendium unter dem Titel Rudimenta Zoologica, ${ }^{16}$ gliedert den Stoff in numerierte Paragraphen ,als bloßer Leitfaden zur Classification der natürlichen Körper", wie Forster zu Beginn seiner Arbeit daran im März 1786 an Christian Gottlob Heyne schrieb; ${ }^{17}$ Forster diktierte es seinen Studenten in eigens dazu bestimmten Stunden nach und nach in die Feder. ${ }^{18}$ Dieser Gliederung folgt im großen Ganzen das dritte Manuskript, die Praelectiones Zoologicae, also der eigentliche Vorlesungstext. ${ }^{19}$ Der einleitende Hauptteil bietet, der Ankündigung in der Adlocutio gemäß, Darlegungen zu allgemeinen physiologischen und anatomischen Themen wie Körperbau, Ernährung, Atmung, Blutkreislauf, Sinnesorganen und Fortpflanzung; eingeflochten sind prinzipielle methodische und erkenntniskritische Erörterungen $\mathrm{zu}$ Blumenbachs Bildungstrieb, zum Seelenbegriff, zur Präformations- und zur Epigenesistheorie sowie zur Taxonomie, eine Bibliographie und ein historischer Rückblick mit einer vergleichenden Würdigung Linnés und Buffons und dergleichen. Bei alldem wird der Mensch ausdrücklich

15 „Quippe illum mancam sane et imperfectam animalium cognitionem habere oportet, qui functionum vitalium, in quibus ut ita dicam, ipsa consistit animalitas, ignarus esset; ast qualem, quaeso, functionum vobis notionem abstrahere poteritis, nisi cognita vasculorum et partium internarum varia structura, in quibus hae functiones aut peraguntur, aut quorum auxilio fiunt? Necessitas inde potissimum elucet, praemittendae alicuius circa internam structuram animalium, quanquam brevissima epitome correptae doctrinae." AA VI 1063.

16 AA VI 1477-1509.

17 AA XIV 446.

18 Vgl. AA VI 1712.

19 AA VI 1511-1719. Dieses Manuskript wird erwähnt von Ilse Jahn: „Scientia Naturae - Naturbetrachtung oder Naturwissenschaft?" Georg Forsters Erkenntnisfragen zu biologischen Phänomenen in Vorlesungs-Manuskripten aus Wilna und Mainz (1786-1793). In: Georg Forster in interdisziplinärer Perspektive. Beiträge des Internationalen Georg Forster-Symposions in Kassel, 1. bis 4. April 1993. Hrsg. im Auftr. d. Georg Forster-Ges. v. Claus-Volker Klenke in Zusammenarb. m. Jörn Garber u. Dieter Heintze. Berlin: Akademie Verl. 1994. S. 159-177. Offensichtlich hat sie jedoch lediglich das erste Drittel des Manuskripts eingesehen ( $\mathbb{S}$ 1-17), wozu der Abschnitt über den Menschen nicht gehört. Der Druck der Praelectiones enthält Schreib-, Lese- oder Druckfehler, die beim Vergleich der auf Blumenbach beruhenden Partien mit ihrer Vorlage besonders deutlich hervortreten. In meinen Zitaten emendiere ich solche Stellen und biete die jeweilige Druckversion in eckigen Klammern. 
einbezogen, oft schon mit Betonung seiner Sonderstellung unter den Tieren, etwa bei der Tastfähigkeit der Finger, bei Gehirn und Nerven, Instinkten und Gedächtnis, den Anlagen zu Lachen, Weinen und zur Sprache. Der darauf folgende klassifizierende Abschnitt bedenkt die Ordnungen der Säugetiere nur mit Stichworten, während dem Menschen, im Kompendium wie in der Vorlesung, mit dem unverhältnismäßig eingehend ausgearbeiteten Paragraphen 50 ein überaus umfangreicherer Anteil eingeräumt wird, so daß die spezielle Naturgeschichte des Menschen mit mehr als 50 Druckseiten ein ganzes Viertel der gesamten Vorlesung ausmacht. ${ }^{20}$ Schon dieses quantitative Verhältnis zeigt, $\mathrm{da} B$ die Anthropologie zu dieser Zeit Forsters Interesse überwiegend in Anspruch nahm. Derart prominent über seinen Kontext hinausragend, verdient der Paragraph die gesonderte eingehende Untersuchung, die hier folgt.

In der Untergliederung des Paragraphen klaffen Kompendium und Vorlesung an einigen Punkten auseinander, worin sich zwei verschiedene Vorlagen bemerkbar machen. Dem Kompendium liegt anfangs das Kapitel über den Menschen in Linnés Systema naturae zugrunde, das sich, stichworthaft knapp gefaßt, dazu am besten eignete, wenn Forster auch bemerkt, es müsse „hier und da verbessert“ werden. ${ }^{21}$ Tatsächlich erfährt Linnés Text unter Forsters Händen schwerwiegende, auch methodisch abweichende Eingriffe: während Linné die Arten gewöhnlich nur durch rein äußerlich erkennbare Merkmale unterschied, fügt Forster charakterisierende Angaben hinzu, die wesentliche Eigenheiten des Menschen betreffen, wie die Zweihändigkeit, den aufrechten Gang und die anatomischen Voraussetzungen dazu, das Fehlen des Zwischenkieferknochens sowie Sprache und Vernunft in enger Verbindung miteinander. ${ }^{22}$ Dies

20 Im Kompendium: „£. 50. I. Homo““ AA VI 1503-1507; in der Vorlesung: ,ad \$. 50. Homo." AA VI 1660-1712. Nach Auskunft von Klaus-Georg Popp ist der Paragraph 50 als selbständiges Manuskript überliefert.

21 „Nobis Linnaeana dispositio, quae facilitate se commendat, hinc inde emendata, prae ceteris arridet." AA VI 1499. Forster benutzt: Caroli a Linné Systema naturae per regna tria naturae, Secundum Classes, Ordines, Genera, Species, cum characteribus, differentiis, synonymis, locis. Ed. duodecima, reformata.T. I. Stockholm: Salvius 1766. Dort beginnt das Kapitel über den Menschen auf S. 28, was Forster AA VI 1503 angibt.

22 „Manus in palmis pedum anteriorum. Incessus erectus, in calcaneis pedum posteriorum. Os intermaxillare nullum! Loquela ratiocinio conjuncta.“ „Corpus (ipsa sua conformatione) erectum“; „Differt itaque a reliquis mammalibus: Corporis situ erecto, manibusque duabus; at interna structura Cerebri, ossis intermaxillaris defectu et pluribus aliis notis physicis; inprimis vero Loquela, cum Ratione coniunctissima." AA VI 1503, 1505. 
weist voraus auf die thematischen Schwerpunkte der Vorlesung, von der hier eine vorläufige Gliederung angehängt wird. ${ }^{23}$

Andererseits läßt Forster ohne ein Wort der Erklärung große Teile von Linnés Beschreibung des Menschen kurzerhand aus: so fehlen bei ihm alle von Linné erwähnten Unter- und Nebenarten, wie die aus fragwürdigen Quellen übernommenen sagenhaften Monstrosa und Anthropomorpha, auch die sechs bekannten in der Wildnis aufgewachsenen Kinder, die Linné einzeln aufzählt, als vierfüßig, stumm und behaart kennzeichnet und mit dem Namen „Homo ferus“ belegt, als ob sich die zivilisierten Menschen von ihnen unterschieden wie die gezähmten Haustiere von ihren Wildformen. Linnés vier auf die klassischen Kontinente verteilte Rassen ersetzt Forster durch seine eigenen sieben „Exempla“, von denen noch zu reden ist. Bedeutsamer ist, daß Forster hier auch die zweite Art des Menschen unterdrückt, die Linné neben den Homo sapiens stellt, den Homo troglodytes oder nocturnus. Unter dieser Rubrik führt Linné auch den „Homo sylvestris Orang Outang“" auf. Diesen versetzte Forster, anderen Zoologen folgend, bereits in seiner Kasseler Vorlesung über die Säugetiere als „Simia Satyrus“ ins Geschlecht der Affen, während er dort allerdings auch noch behauptete: „Der Troglodytes ist ein wahrer Mensch und kein Affe.“24 Diese fiktive Menschenart läßt er erst in der Wilnaer Vorlesung endgültig fallen und schränkt nun mit seiner radikalen Kürzung der Linnéschen Vorlage die Gattung (genus) Mensch auf eine einzige Art (species) ein ${ }^{25}$ die von den Affen streng getrennt ist. Damit verwirft er stillschweigend den gesamten ,fabelhaften Wust“, mit dem, wie Johann Friedrich Blumenbach um diese Zeit unwillig befand, „die Menschen die N[atur] G[eschichte] ihres Geschlechts verunreinigt haben“. ${ }^{26}$

\section{AA VI 1505-1507.}

24 AA VI 971.

25 Dem heutigen Sprachgebrauch entsprechend übersetze ich konsequent ,genus“ mit „Gattung“ und „species“ mit „Art“. Wie sich im Folgenden wiederholt zeigen wird, benutzen Forster und seine Zeitgenossen dagegen oft das Wort „Gattung“ für den systematischen Terminus „,species“ sowie „Geschlecht“ für "genus“.

26 „Alle den fabelhaften Wust herzuzählen, womit die Menschen die N[atur] G[eschichte] ihres Geschlechts verunreinigt haben, lohnt sich kaum mehr der Mühe: Die vermeintlichen Patagonischen Riesen z. B. sind, von Magalhaens Zeiten bis auf die unsrigen, in den Erzählungen der Reisenden, von zwölf Fuß $\mathrm{zu}$ sechs bis siebenthalb eingekrochen, und bleiben also wenig größer als jeder andre Mensch von guter Statur. Und daß Commersons Quimos und andre Zwergnationen auch nichts als abgeschmackte Erdichtungen waren, ist jetzt nun allgemein bekannt. Die Kackerlacken, Blafards, Albinos oder weiße Mohren sind nicht einmal eine Spielart, geschweige eine besondre Gattung, sondern $\mathrm{Pa}$ - 
So verfolgt Forster konsequent die Richtung weiter, die er bereits bei der Beschreibung seiner Weltumseglung einschlug. Diese ist leider in Deutschland meist in der nur teilweise von ihrem Autor selbst stammenden, höchst unzuverlässigen und lückenhaften deutschen Übersetzung bekannt. Der eigentlich wissenschaftliche Charakter des Werkes tritt dagegen wesentlich markanter hervor in den ausführlicheren Darlegungen und präziseren Formulierungen der authentischen englischen Originalfassung, und diese wird daher unseren folgenden Erörterungen zu Grunde gelegt. ${ }^{27}$

Das Thema, um das es hier geht, beschäftigte die damalige physische Anthropologie als irritierendes Problem, seit Linné 1746 hatte gestehen müssen, er habe als Naturhistoriker nach den Prinzipien seiner Wissenschaft bisher noch kein Kennzeichen finden können, wodurch der Mensch vom Affen zu unterscheiden sei. Er hatte sich damit begnügen müssen, den Menschen durch die unsichtbaren Merkmale Sprache und Vernunft vor den Tieren auszuzeichnen. ${ }^{28}$ Diese Verlegenheit stellte die Aufgabe, eine wissenschaftlich wohlfundierte Abgrenzung zwischen dem Menschen und dem Affen zu finden und damit die Stellung zu bestimmen, die der Mensch im Tierreich einnimmt.

Mit dieser Problematik verquickte sich die Debatte um Rousseaus Konzept eines „homme naturel“, dem als reinem Naturwesen keinerlei

tienten, deren Geschichte mehr in die Pathologie als in die Naturhistorie gehört. Linnés Homo troglodytes ist ein unbegreifliches Gemische aus der Geschichte jener preßhaften kränklichen Menschen, und des Orangutangs: sein Homo lar hingegen ein wahrer Affe. Die in Wildnis unter Thieren erwachsenen Kinder sind klägliche sittliche Monstra, die man eben so wenig, als andre durch Krankheit oder Zufall entstellte Menschen, zum Muster des Meisterstücks der Schöpfung anführen darf. Geschwänzte Völker, von Natur geschürzte Hottentottinnen, Syrenen, Centauren, und alle Fabeln von gleichem Schrot und Korn, verzeihen wir der gutherzigen Leichtglaubigkeit unsrer lieben Alten.“ Johann Friedrich Blumenbach: Handbuch der Naturgeschichte. 3. sehr verb. Ausg. Göttingen: Dieterich 1788. S. 62f.

27 Den Unterschied zwischen den beiden Fassungen demonstrieren etwa die Beispiele in den Anmerkungen 32, 37 und 104; vgl. Ludwig Uhlig: Theoretical or Conjectural History. Georg Forsters Voyage Round the World im zeitgenössischen Kontext. In: Germanisch-Romanische Monatsschrift. 53, 2003. S. 399414, bes. S. 413f.; Uhlig 2004 S. 85-95, 107.

$28,[\ldots]$ \& certe si vera fatebor, qua Historicus Naturalis ex scientiae principiis, nullum characterem hactenus eruere potui, unde Homo a Simia internoscatur; [...] Loquela quidem Hominem a reliquis animalibus distinguere videtur; [...] Ast in nobis quidquam inest, quod visum non subit, unde nostri ipsorum cognitio pendet, utpote nobilissima Ratio, qua Homo cunctis animalibus immane quantum praecellit." In: Carolus Linnaeus: Fauna Svecica Sistens Animalia Svecicae Regni. Stockholmiae: Laurentius Salvius 1746. Praefatio. 
Kultur zuzuschreiben sei. Dem hatte Adam Ferguson als Exponent der schottischen „Theoretical or Conjectural History“ den Satz entgegengestellt, die Kunst, das heißt also die Kultur, gehöre dem Menschen von Natur aus zu: „We speak of art as distinguished from nature; but art itself is natural to man. "29 In Forsters Voyage Round the World, die von der Gedankenwelt der Schotten bestimmt ist, erscheint dementsprechend der Mensch vor allem als Kulturwesen. ${ }^{30}$ Beide Themen wurden ausdrücklich miteinander verknüpft durch einen kurios exzentrischen Außenseiter unter den Schotten: James Burnet, Lord Monboddo, hatte, gerade während der Weltumseglung Forsters, von einem Hinweis Rousseaus angeregt, in seinem Buch Of the Origin and Progress of Language die Hypothese vertreten, die Orang-Utans seien in Wirklichkeit eine barbarische Nation, die nur noch nicht den Gebrauch der Sprache gelernt habe. ${ }^{31}$

In seiner Voyage Round the World bestimmte Forster eindeutig den Standpunkt, den er in diesen Fragen bezogen hatte: Mit gereizter Aggressivität nahm er Partei sowohl gegen jegliche Verwischung der Grenze zwischen Menschen und Affen wie auch gegen die Idealisierung eines kulturlosen Naturzustandes des Menschen und brandmarkte beide gleichermaßen als „,bösartig“ (,ill-natured“). Die erste Begegnung der Expedition Cooks mit Vertretern der melanesischen Rasse auf der Insel Mallicolo, an denen die Reisenden eine gewisse Affenähnlichkeit bemerkten, nahm er zum Anlaß für einen heftigen Angriff auf das sogenannte „Orang-outang system“:

They [scil. the natives] continued about the ship, talking with great vociferation, but at the same time in such a good-humoured manner, that we were much entertained. We had no sooner looked at one of them, that he began to chatter without reserve, and grinned almost like Milton's

29 Adam Ferguson: An Essay on the History of Civil Society. Ed. by Fania OzSalzberger. Cambridge: University Press (1995). S. 12. Vgl. dort S. 14 die eingehendere Auseinandersetzung mit Rousseau.

30 Vgl. Ludwig Uhlig: Theoretical or Conjectural History. Georg Forsters Voyage Round the World im zeitgenössischen Kontext. In: Germanisch-Romanische Monatsschrift. 53, 2003. S. 399-414; Uhlig 2004 S. 86-94.

31 „As I have so often mentioned this race of animals, I think it proper to give here a more particular account of them than I have hitherto done; being, according to my hypothesis, a barbarous nation, which has not yet learned the use of speech." James Burnet, Lord Monboddo: Of the Origin and Progress of Language. Vol. 1. 2nd ed. With large Additions and Corrections. Edinburgh: Balfour; London: Cadell 1774. S. 270; die erste Auflage des Werks erschien 1773; vgl. Arthur O. Lovejoy: Monboddo and Rousseau. In: Ders.: Essays on the History of Ideas. Baltimore: Johns Hopkins Press 1948. S. 38-61. 
Death. This circumstance, together with their slender form, their ugly features, and their black colour, often provoked us to make an ill-natured comparison between them and monkies. We should be sorry, however, to supply Rousseau, or the superficial philosophers who re-echo his maxims, with the shadow of an argument in favour of the Orang-outang system. We rather pity than despise these men, who can so far forget and abuse their own intellectual faculties, as to degrade themselves to the rank of baboons. ${ }^{32}$

Mit dieser Polemik stand Forster nicht allein. Genau so empört wandte sich fast zur gleichen Zeit Johann Friedrich Blumenbach in seiner Dissertation De generis humani varietate nativa gegen die Behauptungen Monboddos und ,gewisser berühmter, aber in Naturgeschichte und Anatomie schlecht unterrichteter Zeitgenossen, die sich nicht schämten, den Orang-Utan als dem Menschen nahe verwandt und als Artgenossen

32 AA I 456, vgl. AA III 163f. Dieser Text Forsters wird auf bedenkliche Weise manipuliert von Tanja van Hoorn: Dem Leibe abgelesen. Georg Forster im Kontext der physischen Anthropologie des 18. Jahrhunderts. Tübingen: Niemeyer (2004) [weiterhin zitiert als: van Hoorn 2004]. S. 54, 74f. Entgegen ihrem Versprechen, im Zweifelsfall auch die englische Originalfassung heranzuziehen (van Hoorn 2004 S. 23), zitiert sie davon nur die an dieser Stelle wie so oft äußerst freie deutsche Übersetzung, die vor allem in dem folgenden Satz keinerlei Äquivalent für das scharf verurteilende Epitheton ,,ill-natured“ enthält: „Dieser Umstand, nebst ihrer schlanken Gestalt, Häßlichkeit und schwarzen Farbe, machte, daß sie uns beynahe als ein Affen-Geschlecht vorkamen." (AA III 163, van Hoorn 2004 S. 54.) An diesem Punkt bricht sie ihr Zitat ab und behauptet, Forster gestehe hier, ,daß sich ihm und den anderen Europäern die Frage gestellt habe, ob es sich bei diesen Lebewesen vielleicht gar nicht um Menschen, sondern vielmehr um Affen handeln könne." Van Hoorn verschweigt, daß der zitierten Episode freundliche gegenseitige Annäherungen unter symbolischen Gesten, Geschenkaustausch und Verständigungsversuchen vorangegangen waren, die den Gedanken, es könne sich um Affen handeln, überhaupt nicht zuließen (AA I 454f., vgl. AA III 161-163). Schon dieser Kontext entwertet den ,ill-natured comparison between them and monkeys" zu einer bloßen überheblichen Verspottung, die unter den Reisenden aufkam und von der Forster sich sofort heftig distanziert mit den folgenden Sätzen. Diese aber trägt van Hoorn erst in ihrem nächsten Kapitel nach mit der Bemerkung, daß Forster damit die „Bewohner Malekulas sehr wohl und sehr schnell eindeutig den Menschen zuordnen“ konnte (van Hoorn 2004 S. 74f.). Indem sie den Text aus seinem Zusammenhang löst und auseinanderreißt, suggeriert sie, daß Forster ,die Bewohner Malekulas einen Moment lang (beinahe) für Affen hält" (van Hoorn 2004 S. 74), womit sie einen Exkurs über die seinerzeit schon überholte Anthropomorphendiskussion rechtfertigt, die gerade für Forster völlig irrelevant ist. 
zu bezeichnen" ".33 Blumenbachs Buch erschien kurz bevor Forster seine Voyage Round the World niederschrieb, und die Ähnlichkeit der beiden Invektiven erlaubt die Vermutung, daß Forster hier einer Anregung Blumenbachs folgt. Dieser konnte umgekehrt schon Forsters Beschreibung der Mallicolesen zitieren, mitsamt dem Hinweis auf die Affenähnlichkeit ihrer Schädel. Diese Einzelheit hatte Lichtenberg 1775 in London im Gespräch mit Forster erfahren und nach Göttingen überbracht, wo sie den Weg in Blumenbachs Abhandlung fand; diese bietet damit wahrscheinlich den frühesten wissenschaftlichen Niederschlag von Forsters Südsee-Erfahrungen. ${ }^{34}$ Auch Georg Forsters Vater machte sich in seinen Observations Made during a Voyage round the World derb lustig über Monboddos Orang-Utan-These: wer auf dieser Meinung bestehe, solle sich ausschließlich mit Affen paaren dürfen; er berief sich auf Blumenbachs Dissertation und die Untersuchungen früherer Anatomen zu den anatomischen Voraussetzungen des aufrechten Gangs beim Menschen. ${ }^{35}$ Wie sich zeigen wird, gewann Blumenbachs Arbeit bald größere Bedeutung für Georg Forster.

33 „Ad hoc praesertim incitarunt nuperorum quorundam Cl. quidem Virorum, rei autem naturalis et anatomicae male doctorum sententiae qui hanc simiam [scil. oran-utan] homini satis cognatam et cospeciem dicere haud erubuerunt." In: Johann Friedrich Blumenbach: De generis humani varietate nativa liber. Göttingen: Vandenhoeck 1776 [weiterhin zitiert als: Blumenbach 1776]. S. 36.

34 „Gratum fore lectoribus speramus si breuem horum hominum descriptionem apponimus, quam ex Cl. FORSTERI jun. relatione depromtam, Exc. LICHTENBERG nobiscum communicauit. Praeter omnem nostram expectationem, inquit, incolas in totum ab omnibus ceteris gentibus, quas adhuc in oceano australi videramus, differentes reperiebamus. Statura parua sunt, raro 5 ped. cum 4. pollicibus excedentes. Artus eorum graciles sunt maleque formati, colore ex nigro fusco, quem cum in facie, tum in magna reliqui corporis parte nigro pigmento magis adhuc intensum reddunt. Caput eorum singularis structurae est, cum a nasi radice retro magis depressum sit quam in aliis hominibus, tantamque cum simiarum capite similitudinem prae se ferat, vt vno ore omnes admirationem nostram super ea testaremur. Nasus vero labiaque eorum non magis deformes quam in ceteris oceani australis gentibus, existunt. Capillitium nigrum, crispum et lanuginosum, barbam autem densam et bene crinitam, minus tamen lanuginosam habent. Fune tam arcte cingunt ventrem, vt hic fere in duas partes diuisus appareat. Nullo cetera tegmine quod videremus vtebantur, vnica excepta machina (virilis membri operculo) quae tamen vt illud tegeret quod pleraque gentes occultare student, tantum aberat, vt magis adhuc illud conspicuum redderet." In: Blumenbach 1776 S. 66, Anm. z; die Anmerkung steht nur in der ersten Auflage des Werks.

35 Johann Reinhold Forster: Observations Made during a Voyage round the World. Ed. by Nicholas Thomas, Harriet Guest, and Michael Dettelbach, with a linguistic appendix by Karl H. Rensch. Honolulu: University of Hawai'i Press (1996) [weiterhin zitiert als: J. R. Forster 1996]. S. 172-174. 
Ein gefangener Orang-Utan am Kap der Guten Hoffnung gab Forster die Gelegenheit, seine Verachtung für Monboddos These mit einem Witz auf dessen Kosten zu bezeugen: diese Tierart habe die Ehre, von einigen Philosophen als naher Verwandter adoptiert worden $\mathrm{zu}$ sein. ${ }^{36}$ Die kümmerliche Existenz der Feuerländer, die, auf einer sehr niedrigen Kulturstufe stehend, dem Bild des vernunftlosen Naturmenschen nahe kamen, nahm Forster zum Anlaß, die Vorzüge der Zivilisation zu preisen gegen Rousseaus ,ill-natured system of philosophy“, das er auf Senecas Stoizismus zurückführte. ${ }^{37}$ Die Polemik gegen Rousseaus Naturmenschen zieht sich wie ein roter Faden durch Forsters weitere Schriften, von der Kasseler Rede De la Félicité des Êtres physiques bis hin zu den späteren Essays, ${ }^{38}$ und verrät ihre Herkunft aus der schottischen Philosophie am deutlichsten im einleitenden Absatz des Artikels Neuholland und die brittische Colonie in Botany-Bay mit seinem Protest gegen den erdichteten „Widerspruch zwischen Natur und Cultur“ beim Menschen. ${ }^{39}$

So lag es nahe, daß Forsters Vorlesung den Paragraphen 50 eröffnet mit der Frage nach der Stellung des Menschen unter den Tieren. Dessen Geistesgaben erheben ihn weit über das Tierreich, seine Leiblichkeit setzt ihn mitten hinein. Das Dilemma, das hier vorliegt, führte zu unterschiedlichen Einordnungen der Systematiker, die Forster im Vorübergehen aufzählt. Er selbst versucht, der delphischen Mahnung „Erkenne dich selbst“, die Linné an den Anfang seiner Kennzeichnung des Menschen stellt und die zahlreichen wissenschaftlichen Disziplinen ihre Aufgabe vorschreibt, für seinen Teil mit einer Naturgeschichte des Menschen (,hominis historia naturalis") zu gehorchen. Bereits in der Ankündigung seiner Vorlesung des Jahres 1786/87 hatte er versprochen, dieses Thema bevorzugt zu behandeln; die vorwegnehmende Überschau, die dort gegeben wird, stimmt allerdings nicht ganz mit der endgültigen Anlage der Vorlesung überein. ${ }^{40}$ Daran wie an gewissen Diffe-

36 AA I 645, vgl. AA III 418.

37 AA I 618, Anm.; in der deutschen Übersetzung, AA III 384, fehlt wiederum jegliche Entsprechung des Adjektivs ,,ill-natured“"

38 AA VIII 100; vgl. Uhlig 2004 S. 133, 209, 228, 245.

39 AA V 161f.; vgl. Uhlig 2004 S. 204.

40 „In priore parte singulares generis humani varietates, colore, forma, habitu dissimiles recensebit, postremo vero, de generatione hominis, de instinctu, de alimentorum genere, de climatis in corpus humanum potentia, de hominum per orbem distributione et numero, de eorum ad reliquas animalium species proportione, nec non denique de mirabili, quae homines inter et bestias intercedit differentia physica, nempe de loquelae organo, et cum eodem conjunctó ratiocinio, nonnulla pertractabit. Postquam disserendo de hominis 
renzen zwischen den drei Manuskripten der Vorlesung zeigt sich, daß Forster bis zuletzt an deren Text arbeitete und änderte.

Forster zitiert nun über lange Strecken hin aus der Abhandlung De generis humani varietate nativa von Johann Friedrich Blumenbach. Die zunächst wortgetreue Wiedergabe wird nach einigen Seiten unmerklich durchbrochen von Umformulierungen, raffenden Paraphrasen, Auslassungen und Umordnungen des Materials, bis sich die Vorlesung schließlich entschieden von dieser Vorlage entfernt. So bestimmt Blumenbachs Werk Forsters prinzipiellen Ansatz und bietet andererseits den Ausgangspunkt, an dem sich dessen eigener Beitrag zum Thema deutlich abhebt.

Hier ist der Ort, die Beziehungen zwischen den beiden Männern zu rekapitulieren. Die erste Berührung war, wie gesagt, durch Lichtenberg vermittelt worden, und bei diesem lernten sie sich Ende 1778 kennen, als er die prominentesten Göttinger Professoren zu einem Gastmahl zu Forsters Ehren lud. Der erste Jahrgang des von Lichtenberg zusammen mit Forster herausgegebenen Göttingischen Magazins der Wissenschaften und Litteratur enthielt Blumenbachs ersten Entwurf zu seiner Theorie des Bildungstriebs. ${ }^{41}$ Weitere Konstellationen differenzierten die Beziehungen zwischen ihnen: Forster nahm für seinen Freund Samuel Thomas Soemmerring Partei, als sich zwischen diesem und seinem Fachgenossen Blumenbach Spannungen ergaben. Andererseits war Forsters Mentor und Schwiegervater Christian Gottlob Heyne mit Blumenbach verschwägert, und dessen Nichte Therese Heyne, Forsters spätere Frau, war ihm durch eine gemeinsame Familienreise in die Schweiz verbunden. Nach seiner Abkehr vom positiven Christentum in Wilna ${ }^{42}$ reagierte Forster heftig auf die Zugeständnisse an die kirchliche Autorität, die er in Blumenbachs wissenschaftlichen Aussagen wahrnehmen mußte (darauf wird hier noch näher eingegangen). Beschäftigt mit seinen Vorlesungen und den daraus hervorgehenden Projekten für verschiedene Lehr- und Handbücher zur Naturgeschichte, hielt Forster die fortschreitenden naturhistorischen Arbeiten Blumenbachs mit eifersüchtigem Interesse im Auge, um, vergleichend und kontrastierend, seine eigenen

natura, celeberrimo illi $\eta \gamma \nu \omega \tau$ t $\delta \varepsilon$ aUtov (seu nosce te ipsum!) vetustatis apollinari placito fecerit satis, ad enumerationem singulorum animalium quae classem mammalium constituunt, transibit:“ In: Prospectus Lectionum in Alma Academia et Universitate Vilnensi ex Anno 1786. in 1787. propositus. Demnächst in AA VI/3. Vgl. Uhlig 2004 S. 181.

41 Prof. Blumenbach über den Bildungstrieb (Nisus formativus) und seinen Einfluß auf die Generation und Reproduction. In: Göttingisches Magazin der Wissenschaften und Litteratur. I. St. 5. S. 247-266.

42 Vgl. Uhlig 2004 S. 179f., 196, 205. 
Vorhaben daran zu messen. Noch in Mainz blieb er mit Blumenbach in Verbindung und wurde von dessen anwachsender Sammlung von Menschenschädeln zu dem nie wirklich ausgeführten Vorhaben angeregt, selbst eine solche Sammlung anzulegen.

Es war die 1781 überarbeitete zweite Auflage von Blumenbachs Dissertation, die Forster in seiner Wilnaer Vorlesung benutzte. ${ }^{43}$ Sein Zitat beginnt mit der Erörterung der Instinkte: Im Vergleich zu den Tieren hat der Mensch nur wenige Instinkte, vor allem fehlt ihm jederlei „Kunstinstinkt" (,,instinctus artificialis“), der die Tiere je nach ihrer Art zur Anfertigung von Nestern, Waben, Spinnennetzen und dergleichen antreibt. Stattdessen besitzt der Mensch die Vernunft, die ihm allerdings nicht direkt angeboren, sondern als bloße Möglichkeit gegeben ist und nur unter der Förderung des geselligen Umgangs, des Unterrichts und der Übung heranwächst. Sind die Instinkthandlungen der Tiere notgedrungen, so entspringen die Handlungen der Menschen meist dem freien Willen. Die Tiere sind durch ihre Instinkte jeweils auf ein voraus bestimmtes Klima, eine Nahrungs- und Lebensweise genau und unabänderlich angewiesen. Der Mensch dagegen, der Herr der Schöpfung, muß sich allen Klimaten der Erde und allen Lebensweisen anpassen und darf nicht auf eine einzige Umweltsituation eingeschränkt werden; da ihm alles zur Nahrung dienen soll, wäre ihm auch mit einem spezifischen Kunstinstinkt nicht geholfen. Die unbeschränkte Anpassungsfähigkeit des Menschen an alle auf der Erde vorhandenen Lebensbedingungen hatte Forster schon 1785 in seiner Vorlesung De hominis in omni climate vivendi facultate demonstriert. ${ }^{44}$

Mit der Vernunft untrennbar verbunden ist die Sprachfähigkeit, beide sind zu ihrer Entwicklung auf Unterricht und Geselligkeit angewiesen. Wenn viele ,wilde“ und entlegene Völkerschaften auch keine Schrift kennen, so haben sie doch alle ihre eigentümliche Sprache mit bestimmtem Vokabular. Dies hatten Forster und sein Vater während der Weltreise selbst erfahren, und da die Sprachfähigkeit als menschliches Privileg galt, verlieh ihr Interesse an diesen Sprachen ihren anthropologischen Studien insgesamt von vornherein einen prinzipiell anderen

43 Johann Friedrich Blumenbach: De generis hvmani varietate nativa liber. Göttingen: Vandenhoek [sic!] 1781 [weiterhin zitiert als: Blumenbach 1781]. Forsters Zitat beginnt auf S. 19, wie er selbst angibt (AA VI 1661). Hier ist zu bemerken, daß die dritte Auflage von Blumenbachs Werk von 1795, die durch ihre deutsche Übersetzung von Johann Friedrich Gruber (Leipzig: Breitkopf und Härtel 1798) weitere Verbreitung fand, eine völlig neue Bearbeitung darstellt, in der gerade die für Forster relevanten Abschnitte kaum wiederzufinden sind.

44 AA VI 1045-1060; vgl. Uhlig 2004 S. 198f. 
Charakter als ihren Naturforschungen: Indem sie die Sprachen der neuentdeckten Völker zu erlernen und sich mit diesen $\mathrm{zu}$ verständigen suchten, erkannten sie die fremden Menschen ohne Zögern als ihresgleichen an. Das Ethos, allen Menschen die gleichen Rechte wie sich selbst zuzuteilen, formulierte Georg Forster im Vorwort zur Voyage Round the World programmatisch in naturrechtlicher Terminologie. ${ }^{45}$ Auch die scheinbar affenähnlichen Mallicolesen hatten sich schon bei der ersten Begegnung mit belustigender Geschwätzigkeit als sprechende Menschen vorgestellt, und dies allein disqualifizierte die Vermutung, es handle sich vielleicht um Affen, als absurd und „,ill-natured“. Wenn die Reisenden ihre Sprache zunächst nicht verstanden, so mußten sie ihnen bei näherer Bekanntschaft besonders erstaunliche Sprachtalente zusprechen.

Wie Blumenbach weiter ausführt, haben im Gegensatz zum Menschen gerade die Tiere, die ihm mit ihrem Körperbau am nächsten stehen, keine zum Sprechen geeignete Stimmorgane. Petrus Camper hatte nachgewiesen, daß die Affen, zumal der Orang-Utan, durch den Bau ihres Kehlkopfs daran gehindert werden, artikulierte Laute hervorzubringen und eine Sprache $z u$ entwickeln, und Samuel Thomas Soemmerring hatte dies mit einem Artikel in Lichtenbergs Göttinger Taschen Kalender für 1781 bekanntgemacht. Darauf hatte sich Forster bereits in seiner Vorlesung von 1785 berufen. ${ }^{46}$

Blumenbachs Darlegungen unterbrechend, schärft Forster mit eigenen Worten in nachdrücklichen Wiederholungen die unlösbare Verbindung zwischen Sprache, Vernunft und Gesellschaft ein:

Und die Sprache ist ja mit der Ausbildung der Vernunft durch einen untrennbaren Zusammenhang verbunden und sprießt zusammen mit der Vernunft hervor; niemals ist beim Menschen Vernunft ohne Sprache oder Sprache ohne Vernunftgebrauch zu finden. Beide aber wachsen gleichsam

45 ,Accustomed to look on all the various tribes of men, as entitled to an equal share of my good will, and conscious, at the same time, of the rights which I possess in common with every individual among them, I have endeavoured to make my remarks with a retrospect to our general improvement and welfare; and neither attachment nor aversion to particular nations have influenced my praise or censure." AA I 14, vgl. AA II 13f.; vgl. Uhlig 2004 S. 93-95.

46 AA VI 1107-1109; vgl. [Samuel Thomas] S[oemmerrin]g: Etwas vernünftiges vom Orang Utang. In: Göttinger Taschen Kalender 1781. 40-64, bes. 43f., $63 \mathrm{f}$. Fälschlich schreibt van Hoorn 2004 S. 62f., diesen Aufsatz Lichtenberg zu; vgl. Uhlig 2004 S. 181f. Noch in seiner Kasseler Vorlesung über die Säugetiere hatte Forster allerdings behauptet, die Organe im Hals der Affen seien ,so wie die unsrigen zur Sprache geschickt, und ist daher zu bewundern daß sie nicht auch die Sprache nachahmen." AA VI 969. 
unter der Kinderpflege des Gesellschaftslebens auf, insofern nämlich, daß zwar die Fähigkeit, die Sprache zu erwerben und die Vernunft auszubilden, dem Menschen eingeboren ist, die Sprache selbst aber, ebenso wie die Vernunft, nur durch die Schulung und die Erfordernisse des Gesellschaftslebens voll entwickelt wird. ${ }^{47}$

Mit dem Begründungszusammenhang zwischen dem Mangel an Kunsttrieben einerseits und der Fähigkeit zu Vernunft und Sprache andererseits beim Menschen griff Blumenbach zurück auf Herders Abhandlung über den Ursprung der Sprache, wo den mit ihren Instinkten auf eine enge Sphäre angewiesenen Tieren der Mensch gegenübergestellt wird, der mit seiner eigentümlichen Besonnenheit frei wirkend in die Welt ausgreift und selbst seine Sprache erfindet. Blumenbach erwähnt Herder nicht direkt, aber er verweist auf einen anonymen Artikel im Teutschen Merkur, der „diese Herderische Erklärung der thierischen Kunsttriebe“ diskutiert, und wendet sich wie Herder gegen die These Johann Peter Süßmilchs, die Sprache sei durch göttliche Inspiration entstanden. ${ }^{48}$

Was Forster angeht, so hatte er noch in seiner Vorlesung vom Frühjahr 1785 das Verhältnis zwischen Vernunft und Sprache eher im Sinne von John Lockes Essay Concerning Human Understanding bestimmt und zur selben Zeit scherzhaft bemerkt, daß Blumenbach den Menschen den

47 „Et ea [scil. loquela] quidem cum rationis cultura inseparabili quodam nexu coniuncta, simul cum ratione progerminat; neque rationem absque loquela, neque loquelam absque rationis usu, unquam in homine reperies. Utraque autem Vitae socialis quasi filia cura prodit, ita quidem ut facultas loquelam adipiscendi et rationem excolendi homini innata sit, ipsa vero loquela pariter ac ratio nonnisi institutione et socialis vitae necessitudine perficiatur." AA VI 1664; Forsters Zutat ersetzt Blumenbachs Ablehnung der These Süßmilchs, die Sprache sei den Menschen durch göttliche Inspiration verliehen worden: „Et ea [scil. loquela] quidem primam excultae rationis germinationem necessario sequitur, ita vt non ad divinam quandam linguae reuelationem cum SÜSSMILCHIO refugere, sed eandem pro absolute necessaria cultae rationis consequentia habere, opus sit." Blumenbach 1781 S. 24. Der Nachdruck, mit dem Forster hier die unlösliche Verknüpfung zwischen Sprache und Vernunft betont, könnte darauf hindeuten, daß er, unabhängig von Blumenbach, direkt auf Herders Abhandlung Über den Ursprung der Sprache zurückgeht.

48 Vgl. Johann Gottfried Herder: Werke in zehn Bänden. Hrsg. v. Günter Arnold u.a. (Frankfurt am Main): Deutscher Klassiker Verl. (1958-2000) [weiterhin zitiert als: Herder]. Bd I S. 711-733, sowie: [Anon.]: Anmerkungen zu einer Stelle in Reimarus Betrachtungen über die Triebe der Thiere, den Unterschied der menschlichen und thierischen Seelen betreffend. In: Der Teutsche Merkur. 1775. 3. Viertelj. S. 196-213, 4. Viertelj. S. 16-32, Zitat S. 20; auf diesen Artikel verweist nur Blumenbach 1776 S. 20, Anm. f), auf Süßmilch nur Blumenbach 1781 S. 24. 
Instinkt ,gern abdisputirte“. ${ }^{49}$ Aber er verfolgte mit wachsender Anteilnahme den Fortgang von Herders Ideen zur Philosophie der Geschichte der Menschheit und stand seit seinem Besuch bei Herder im September 1785 unter dem starken Eindruck von dessen Persönlichkeit. ${ }^{50}$ Daß er dabei auch mit Herders Abhandlung über die Sprache bekannt wurde, bezeugt spätestens seine Lobschrift auf Cook. Dort schreibt Forster dem Menschen als hervorragenden Charakterzug die „Besonnenheit“ zu; dieses Wort hatte Herder in seiner Abhandlung mit terminologischem Nachdruck eingeführt, um die „ganze Disposition“ der menschlichen Natur zu kennzeichnen. ${ }^{51}$ Wenn Forster die „Perfectibilität“ als „die angewandte Besonnenheit" bezeichnet, ${ }^{52}$ so verschmelzen hier die Gedanken Herders mit dem Menschenbild der schottischen „Theoretical or Conjectural History“. Diese Vereinigung fiel Forster um so leichter, als auch in Herders Argumentation Rousseaus „Phantom, der Naturmensch; dieses entartete Geschöpf", eine scharfe Ablehnung erfährt. ${ }^{53}$ Alldem entspricht der thesenhaft prägnant formulierte Satz, den Forster als eines der zwanzig Resultate der Reisen Cooks aufstellt:

19. daß, so wie es kein Volk ohne Sprache, und keine Sprache ohne Vernunft giebt, so auch keinen blos thierischen Stand der Natur. ${ }^{54}$

Herausgefordert von Linnés Unfähigkeit, zwischen Menschen und Affen zu unterscheiden, unternimmt es Blumenbach nun, die Eigenheiten des menschlichen Körperbaus herauszuarbeiten, die ihn unbezweifelbar von den Affen und überhaupt von allen anderen Tieren unterscheiden. ${ }^{55}$ Das hervorstechendste Merkmal ist der aufrechte Gang, zu dem der Mensch durch die Gestaltung seiner Gliedmaßen, aber auch des inneren Körperbaus vorausbestimmt scheint. Auf seinen flachen Fußsohlen, wie sie kein anderes Tier besitzt, kann der Mensch aufrecht stehen und gehen und hat dabei seine Hände mit ihren Fingern frei zum Gebrauch als Werkzeuge. Es war leicht, Pietro Moscati zu widerlegen, der, von Rousseau angeregt, behauptet hatte, der Gang auf allen Vieren sei auch für den Menschen natürlich und die aufrechte Haltung sei ungesund; auch die oft angeführten in der Wildnis aufgewachsenen Kinder

49 AA VI 1107f., XIV 285; vgl. Uhlig 2004 S. $181 f$.

50 Vgl. Ludwig Uhlig: Georg Forster und Herder. In: Euphorion. 84, 1990. S. 339-366 und Uhlig 2004 S. 186f.

51 Herder Bd I S. 719-722. Das Wort „Besonnenheit“ findet sich auch in Herders Ideen (Herder Bd VI S. 159), aber nur beiläufig.

52 AA V 195.

53 Herder Bd I S. 730.

54 AA V 280; vgl. Uhlig 2004 S. 208 f.

55 Blumenbach 1781 S. 26-42. 
boten keinen Gegenbeweis. Im Gegensatz zu dem zweihändigen Menschen ist der Affe eigentlich ein Vierhänder, der seine hinteren Hände beim Klettern braucht, um sich an Ästen festzuhalten wie ein Eichhörnchen. Forster, der in allen diesen Punkten weiterhin Blumenbach folgt, kann hier zur Bestätigung seine eigene Beobachtung des Orang-Utans vom Kap beitragen, der nur mühsam und möglichst auf einen Stock gestützt aufrecht gehen konnte. ${ }^{56}$

Blumenbach betont das Fehlen jeglicher natürlicher Waffen beim Menschen, der nackt und bloß, ohne stoßende Hörner, reißende Klauen oder Zähne in die Welt gesetzt wird und während seiner langen Kindheit besonders hilflos ist. Diesen Umstand hatte Blumenbach bereits 1775 zum Anlaß genommen, für den Menschen im System der Tiere eine eigene Ordnung der „Unbewaffneten“ (Inermes) aufzustellen. ${ }^{57}$ Diese Einordnung übernimmt Forster nicht, wenn er auch Blumenbachs Schilderung der Waffenlosigkeit bekräftigt, vor allem im Zusammenhang mit der Erörterung des Zwischenkieferknochens (os intermaxillare). Dieser Knochen trägt bei den Säugetieren die oberen Schneidezähne und bildet ein nach vorn ausragendes Maul, das sie befähigt, kräftig zuzubeißen. Dem Menschen dagegen fehlt dieser Knochen, daher ist sein Gebiß kürzer und als Waffe ungeeignet, es dient dafür besser zum Kauen und zum Sprechen. Vor allem durch die Untersuchungen Campers galt seinerzeit der Zwischenkieferknochen als ausschlaggebendes anatomisches Merkmal zur Unterscheidung zwischen den Säugetieren und dem Menschen, und gegen diese herrschende Meinung konnte sich Goethe nicht durchsetzen, als er 1785 auch beim Menschen Spuren dieses Knochens feststellte und zu seiner Enttäuschung keine Anerkennung für seine Entdeckung fand..$^{58}$

Gestützt auf Blumenbach und andere, hatte Herder in seinen Ideen zur Philosophie der Geschichte der Menschheit den aufrechten Gang als vorzügliche Auszeichnung des Menschen vor den Tieren bezeichnet und

56 AA VI 1667.

57 Blumenbach 1781 S. 33; vgl. Johann Friedrich Blumenbach: Handbuch der Naturgeschichte. 3. sehr verb. Ausg. Göttingen: Dieterich 1788. S. 58.

58 Vgl. Manfred Wenzel: Johann Wolfgang von Goethe und Samuel Thomas Soemmerring: Morphologie und Farbenlehre. In: Samuel Thomas Soemmerring und die Gelehrten der Goethezeit. Beiträge eines Symposions in Mainz vom 19. bis 21. Mai 1983. Stuttgart, New York: Gustav Fischer 1985. = Soemmerring-Forschungen I. S. 11-33; ders.: Der gescheiterte Dilettant: Goethe, Soemmerring und das Os intermaxillare beim Menschen. In: Gehirn Nerven - Seele. Anatomie und Physiologie im Umfeld S. Th. Soemmerrings. Stuttgart, New York: Gustav Fischer 1988. = Soemmerring-Forschungen III. S. 289-329. 
begeistert erklärt, dadurch werde der Mensch eine „erhabne Göttergestalt und künstlichste Hauptschönheit der Erde" . ${ }^{59}$ Forster rügte diese überschwengliche Bildlichkeit, die der rein zweckmäßig bildenden $\mathrm{Na}$ tur die Absicht unterstelle, den anthropomorphen Maßstäben von Adel und Schönheit Genüge zu leisten. ${ }^{60}$ Blumenbachs Argumentation für den aufrechten Gang jedoch übernimmt Forster nahezu unverändert in seiner Vorlesung und trägt ihr sogar mit einer neuen Bezeichnung der Menschenart Rechnung: „Homo (Sapiens) erectus“, der denkende, aufrechte Mensch. ${ }^{61}$

Auch im weiteren Verlauf der Darstellung hält Forster sich an Blumenbachs Text, aber er verfügt doch freier über Wortlaut und Anordnung und trägt eigene Ergänzungen bei: Das Lachen etwa gilt ihm nicht nur als Ausdruck der Freude oder eines physischen Affekts, sondern es entsteht aus einem unvermuteten Zusammentreffen kontrastierender Ideen und ist in dieser Hinsicht nur dem Menschen eigentümlich. ${ }^{62}$ Häufiger geht Forster ,sozusagen trockenen Fußes",63 mit knappen Zusammenfassungen über eingehendere Ausführungen Blumenbachs hinweg. Auf dessen spezifizierte Abgrenzungen des Menschen gegen einzelne Affenarten verzichtet Forster gänzlich, womit er diesmal die bereits erwähnte Invektive gegen Monboddo übergeht, die sich ja schon in der ersten Auflage von Blumenbachs Schrift und ähnlich in seiner eigenen Voyage Round the World fand. ${ }^{64}$

Forsters soeben neu errungene Emanzipation vom dogmatischen Christentum findet Ausdruck in einigen unauffälligen Änderungen, mit denen er Blumenbachs Text gelegentlich gewissermaßen säkularisiert, indem er religiöse Wendungen, zumal Erwähnungen Gottes, entweder wegläßt oder durch andere Worte ersetzt. Wo Blumenbach etwa einen zweckdienlichen Umstand in der Entwicklung des Kleinkindskeletts der „höchsten Fürsorge Gottes“ (,summa Dei prouidentia“) zuschreibt, ändert Forster dies in die „höchste Weisheit der Natur" (,summa naturae sapientia“) ${ }^{65}$ Dies tastete allerdings die Intention der betreffen-

59 Herder Bd VI S. 110-115.

60 AA XIV $327 f$.

61 AA VI 1693.

62 „Sed risus verus hominis, ut alio jam loco dixi, non est unice gaudii interpres, aut physicae adfectionis, verùm ex concursu inopinato idearum dissimilium nascitur; et hoc respectu certe homini proprius est.“ AA VI 1668.

63, ,...] sicco ut aiunt pede praeterimus.“ AA VI 1669.

64 Blumenbach 1781 S. 42f., vgl. Blumenbach 1776 S. 36 und AA I 456.

65 Blumenbach 1781 S. 29, Forster AA VI 1666; vgl. Blumenbach 1781 S. 21: „nisi indemne seruaretur diuinae illa particula aurae, ratione inquam, quae sanctiori huic animali, vt OVIDII verba mea faciam, mentisque capaciori altae 
den Formulierungen Blumenbachs kaum an. Ein grundlegendes Axiom der damaligen Naturwissenschaft war die Annahme eines zweckmäßigen Gesamtzusammenhangs der Natur, der mit voraussehender Weisheit so angeordnet sei, daß jede Einzelheit eine unentbehrliche Funktion erfülle und keine überflüssig sei. Für diese Weltvorstellung, die bis in die Antike zurückging, war es gleichgültig, ob als Urheber des Ganzen Gott oder ein mehr oder weniger explizit pantheistischer Naturbegriff postuliert wird. Diese Indifferenz gegenüber der metaphyischen Begründung ist deutlich erkennbar in Forsters Kasseler Vorlesung Ein Blick in das Ganze der Natur. Diese folgt weithin wörtlich den beiden kosmologischen Überblickskapiteln De la Nature in Buffons Histoire naturelle, auch in deren unentschiedenem Schwanken zwischen Deismus und Pantheismus. ${ }^{66}$ Ganz im Sinne Buffons erkannte Forster dort die Natur einerseits pantheistisch als „,natura naturans“ an, als „,thätige, lebendige Kraft, die alles in der uns bekannten Schöpfung wirkt", und beschränkte andererseits ihre Macht auf die eines Demiurgen, da sie „als eine Dienerin der unwiderruflichen Befehle Gottes, und als Bewahrerin seiner unwandelbaren Rathschlüsse,“ nur Gottes Entwürfe ausführe und „das Siegel des Höchsten allen ihren Werken“ aufdrücke; obendrein nötigte Forsters eigener damals noch ungebrochener Kirchenglauben ihn auch noch $\mathrm{zu}$ dem theistischen Vorbehalt, die Natur sei nur eine „Vorbereitung unseres Geistes zu Wundern anderer Art, zum Glauben an jene nachfolgenden Offenbarungen, welche das Heil des Menschengeschlechtes näher betrafen, und die Hoffnungen der Vorwelt erfüllten “". ${ }^{67}$ All diese mühsamen Qualifikationen führten jedoch zu keinerlei Konsequenzen in dem großen Entwurf einer genau abgewogenen Gesamtordnung der Naturkräfte und Lebewesen, der damit eingeleitet wurde.

Religiöse Meinungsverschiedenheiten bestimmten nun dagegen den Punkt, an dem Forsters Vorlesung die Vorlage Blumenbachs entschieden hinter sich läßt und ihren eigenen Weg einschlägt. Abgestoßen wurde Forster offenbar davon, daß es Blumenbach bei der Frage, ob alle Men-

[...] concessa“, dagegen bei Forster: „nisi indemne servaretur ratione quae illi [...] concessa“ (AA VI 1662); Blumenbach 1781 S. 22: „,demumque in diuinam illam et limitum et extinctionis expertem flammam erumpat" wird von Forster weggelassen; Blumenbach 1781 S. 26: „Summi Numinis summum opificium ne dicam“ wird von Forster schlicht ersetzt durch ,hominem“ (AA VI 1665).

66 De la Nature. Première Vue. In: [Georges Louis Leclerc, Comte de Buffon:] Histoire naturelle, générale et particulière, avec la description du Cabinet du Roi. Tome 12ème. Paris: Imprimerie Royale 1764, S. iij-xvj; und: De la Nature. Seconde Vue. Ebenda Tome 13ème. 1765, S. j-xx; vgl. Uhlig 1965 S. 48-50, 267f. und Uhlig 2004 S. 127f.

67 AA VIII 81f. 
schen zu einer einzigen oder zu verschiedenen Arten gehören, nicht nur um naturhistorische Aufschlüsse geht, sondern vor allem um die „Sicherstellung des Glaubens an die Heilige Schrift" ${ }^{68}$ Nur böswillige und leichtfertige Neuerungssucht sieht Blumenbach in jedem Zweifel an der Wahrheit der biblischen Schöpfungsgeschichte. Dies stellte damals durchaus die allgemein verbreitete herrschende Meinung dar. Ganz ähnlich hatte sich auch Johann Reinhold Forster in seinen Observations zu dieser Frage geäußert, und sein Sohn Georg, noch in der exaltierten Frömmigkeit der Kasseler Rosenkreuzer befangen, gab sicher mit vollem Einverständnis die entsprechende Passage in seiner deutschen Übersetzung wie folgt wieder:

Ohne Vorurtheil, ohne eingewurzelte hämische Feindschaft gegen die Offenbarung, wird man also hier allemal entscheiden müssen, daß die so sehr abstechenden Spielarten des Menschengeschlechts alle von einer Gattung sind. Sollte man auch das Ansehen der Schrift, welches Christen nicht in Zweifel ziehen können, dahin gestellt seyn lassen, so würde sie noch immer als die älteste historische Urkunde ihren Werth behaupten, und das obige philosophische Resultat durch ihr Zeugnis bestätigen. ${ }^{69}$

Auf diese, ,ältesten Urkunden über den Ursprung des Menschengeschlechts" berief sich sogar Georg Forster selbst noch in seiner Vorlesung vom Frühjahr 1785, als er den ersten Wohnsitz der Menschen im südlichen Asien lokalisierte, wo ein freundliches Klima und eine fruchtbare Umwelt diese schwachen und wehrlosen Lebewesen beschützt habe, bevor sich deren Geisteskräfte besser entwickelt hätten. ${ }^{70}$

68 „Quaestio de vnica pluribusue generis humani Speciebus. Ardua quidem, sed cum ad vindicandam Sacri codicis fidem, tum ob lucem quam vniuersae generis humani imo et reliquae naturali historiae impertit, vtilissima et dignissima disquisitio." Bumenbach 1781 S. 47.

69 Johann Reinhold Forster: Bemerkungen über Gegenstände der physischen Erdbeschreibung, Naturgeschichte und sittlichen Philosophie auf seiner Reise um die Welt gesammlet. Uebersetzt und mit Anmerkungen vermehrt von dessen Sohn und Reisegefährten Georg Forster. Berlin: Haude und Spener 1783 [weiterhin zitiert als: J. R. Forster 1783]. S. 232. Vgl. Uhlig 2004 S. 135, 139144.

70 „Quod enim ex monumentis vetustissimis de generis humani primordiis intelligitur, Asiae partem meridionalem primam hominum sedem fuisse, ut in hac potissimum orbis regione, ubi clima humano corpori aptissimum est, et naturae divitiae ad vitae necessitates sponte et abunde profluunt, $a b$ interitu servaretur genus debile, et priusquam crebra exercitatione ratiocinandi facultatis vires acquireret, natura sua contra animalium majorum rabiem vix tutum; id etiam plurimum videtur ad inventionem astronomiae naturalis, atque ceterarum omnium scientiarum contulisse." AA VI 1117. 
Blumenbachs Entrüstung hatte vor allem ein Einfall des Theophrastus Paracelsus erregt, der angesichts der Einwohner des neuentdeckten Amerika meinte, Gott habe zwei Adams geschaffen. Auch Soemmerring war an einem Punkt seiner Forschungen zur Anatomie der Afrikaner und Europäer versucht, ,sozusagen zwei Adams“"71 anzunehmen, und hellhörig hatte Blumenbach im Februar 1786 in seiner Rezension der revidierten Fassung von Soemmerrings Abhandlung bemängelt, einige Wendungen der ursprünglichen Fassung hätten die Mißdeutung veranlaßt, daß er sich „,beykommen ließ, noch jetzt mehrere Gattungen (Species) im Menschengeschlecht anzunehmen, oder die gemeinschaftliche Abkunft aller uns bekannten Menschen-Racen von einem einzigen Stamm-Paare zu bezweifeln". ${ }^{72}$

An dieser fraglosen Unterwerfung unter die Autorität der biblischen Schöpfungsgeschichte nahm Forster nun Anstoß, nachdem er sich vom positiven Christentum abgewandt hatte; und in seinem Aufsatz Noch etwas über die Menschenraßen prangerte er Blumenbachs auftrumpfende Rechtgläubigkeit an, indem er dessen zensorische Redeweise sarkastisch pointiert aufgriff:

[...] das Urtheil derer, die sichs beykommen lassen in diesem Punkt vom gewöhnlichen Wege abzuweichen, ist schon gesprochen. Obschon ein altes Buch, wogegen niemand schreiben darf, mit keiner Sylbe des Negers erwähnt; obschon der große Mann, der angebliche Verfasser desselben, vermuthlich keinen Neger je gesehen: so ist es doch ein Angrif auf dieses alte Buch, wenn man von mehr als Einem Menschenstamme sich eine Möglichkeit vorstellt, und dieser Streich, der niemand verwundet, heißt eine Ketzerey. Die Ketzer aber sind boshafte Leute; sie treibt die Neuerungssucht, sie führt die blinde Unwissenheit. ${ }^{73}$

Dieser Seitenhieb verrät die grundlegende Wendung, die sich mittlerweile in Forsters Denken vollzogen hatte und die ihn schließlich auch dahin führte, daß er bei der Frage nach der Abstammung der Menschen die traditionelle Antwort, die Blumenbachs Abhandlung De generis humani varietate nativa ihm bot, verwarf und in der weiteren Fortsetzung seiner Vorlesung völlig unabhängige eigene Gedankengänge verfolgte.

71 „In dies magis magisque persuadeor, aethiopum et Europaeum non varietate sed specie differre, et duos fuisse ut ita dicam Adamos." In: Samuel Thomas Soemmerring: Briefwechsel. 1761/65 - Oktober 1784. Hrsg. u. erl. v. Franz Dumont. Stuttgart, Jena, New York: Gustav Fischer 1996. = Soemmerring: Werke. Bd 18. S. 479.

72 Zitiert nach AA XIV 810.

73 AA VIII 156, vgl. AA XIV 515. 
Unsere Untersuchung dieser Vorlesung muß hier jedoch vorerst einhalten, um zunächst den Artikel über die Menschenrassen als deren Vorgänger zu bedenken. Forster hatte ihn beschlossen mit der Ankündigung, er werde vielleicht einmal auf dessen Thema zurückkommen, und tatsächlich führt seine Vorlesung gewisse Überlegungen fort, die er kurz vorher dort angesponnen hatte. Aber die komplexen Zusammenhänge und Fragestellungen, von denen die Gesamtheit dieser Erörterungen bestimmt wurde, sind nur mit einem weiter ausgreifenden Rückblick angemessen zu würdigen, der, so sehr er gelegentlich von unserem Gegenstand abzuschweifen scheint, doch die unentbehrlichen Voraussetzungen zum Verständnis der anschließenden Argumentation in Forsters Vorlesung aufarbeitet.

Mit dem Aufsatz Noch etwas über die Menschenraßen hatte Forster auf Immanuel Kants Bestimmung des Begriffs einer Menschenrace entgegnet, die im November 1785 in der Berlinischen Monatsschrift erschienen war, jedoch auf einen älteren Artikel aus dem Jahr 1775 zurückgriff, den Kant in leichter Überarbeitung 1777 nochmals veröffentlicht hatte. Diese Schriften stammten also noch aus dem Jahrzehnt, in dem Kant sich in stillschweigender Anstrengung um die Ausarbeitung seiner Kritik der reinen Vernunft bemühte, ${ }^{74}$ aber sie waren von den Gedankengängen der kritischen Philosophie völlig unberührt geblieben, und dies gilt auch noch für den Artikel von 1785, der das ursprüngliche Konzept der früheren Arbeiten fast unverändert übernahm. Kant nimmt vier Menschenrassen an: die „der Weißen, der gelben Indianer, der Neger, und der kupferfarbig-roten Amerikaner" ${ }^{75}$ Die jeweils verschiedene Hautfarbe erklärt er nicht, wie seinerzeit üblich, kausal, als eine Folge von Einwirkungen von außen her. Vielmehr findet Kant darin ,eine von der Natur sehr weislich getroffene Anstalt“", ${ }^{76}$ wodurch die Haut, das Organ der „Absonderung durch Ausdünstung“" ${ }^{77}$ mit einer gewissen ,Zweckmäßigkeit der Organisation " ${ }^{\text {78 }}$ den klimatischen Bedingungen der verschiedenen Wohnorte ,genau angemessen“"79 gefärbt ist: so sind die Weißen der

74 Vgl. Ernst Cassirer: Kants Leben und Lehre. Darmstadt: Wissenschaftliche Buchgesellschaft (1994). S. 129-148; Manfred Kühn: Kant. Eine Biographie. A. d. Engl. v. Martin Pfeiffer. (2. Aufl.) (München): Beck (2004). S. 267-274, 279f. Was Kühn hier S. 397f. über die Kontroverse zwischen Kant und Forster bemerkt, geht völlig an deren eigentlicher Thematik vorbei.

75 Immanuel Kant: Werke in sechs Bänden. Hrsg. v. Wilhelm Weischedel. (Wiesbaden): Insel-Verl.(1956-64) [weiterhin zitiert als: Kant]. Bd VI S. 67.

76 Kant Bd VI S. 79.

77 Kant Bd VI S. 68.

78 Kant Bd VI S. 79.

79 Kant Bd VI S. 73. 
feuchten Kälte, die Gelben der trockenen Hitze, die Schwarzen der feuchten Hitze und die Roten der trockenen Kälte angepaßt. ${ }^{80}$ Zwar vermag Kant, wie er selbst gesteht, die physiologischen Zusammenhänge, die er hier postuliert, nicht genau nachzuweisen, ${ }^{81}$ aber ihm genügt die „Vermutung der Zweckmäßigkeit". ${ }^{82}$ So sehr läßt er sich von der Annahme eines teleologisch angeordneten Plans der Natur leiten. Den teleologischen Gottesbeweis, der auf dieser Annahme beruhte, hatte er zwar selbst widerlegt, er schrieb ihm jedoch sogar noch in der Kritik der reinen Vernunft ausdrücklich eine nützliche heuristische Funktion in der Naturforschung $\mathrm{zu}^{83}$

Kant muß sich nun bemühen, diese These mit einem weiteren Axiom zu vereinbaren, nämlich dem von der Einheit der Menschenart. Diese versteht er genetisch als „Realgattung, als zu welcher durchaus wenigstens die Möglichkeit der Abstammung von einem einzigen Paar erfordert wird" ${ }^{84}$ Hier steht nicht so sehr die Tradition der Naturgeschichte im Hintergrund als vielmehr, wie seinerzeit üblich, die Autorität der biblischen Schöpfungsgeschichte. Kant behauptet, nach Buffon, die Stammesgemeinschaft aller Menschenrassen werde damit bewiesen, daß diese sich miteinander vermischen könnten, wobei aus der „halbschlächtigen Zeugung“ unausbleiblich ein „Mittelschlag oder Bastard" hervorgeht. ${ }^{85}$ Schließlich muß Kant sich doch noch der peinlichen Frage stellen, wie aus dem gemeinsamen Ursprung so stark unterschiedliche Rassen entspringen konnten, und er ist sich bewußt, daß er dieser Frage nicht ausweichen darf, da er sonst „die Einheit der Gattung einbüßete“" .86

Dabei erhebt sich ein unüberwindlicher Konflikt zwischen den Grundprinzipien der damaligen Naturgeschichte. Diese stellten absolute,

80 Kant Bd VI S. 28.

81 Kant Bd VI S. 79.

82 Kant Bd VI S. 80.

83 „Dieser Beweis verdient jederzeit mit Achtung genannt zu werden. Er ist der älteste, kläreste und der gemeinen Menschenvernunft am meisten angemessene. Er belebt das Studium der Natur, so wie er selbst von diesem sein Dasein hat und dadurch immer neue Kraft bekommt. Er bringt Zwecke und Absichten dahin, wo sie unsere Beobachtung nicht von selbst entdeckt hätte, und erweitert unsere Naturkenntnisse durch den Leitfaden einer besonderen Einheit, deren Prinzip außer der Natur ist." Kant Bd II S. 550f. Vgl. Holm Tetens: Kants „Kritik der reinen Vernunft“. Ein systematischer Kommentar. Stuttgart: Reclam (2006). S. 19f., bes. Anm. 6.

84 Kant Bd VI S. 78.

85 Kant Bd VI S. 70.

86 Kant Bd VI S. 78. 
nicht hinterfragbare Prämissen dar, ${ }^{87}$ die dem Bewußtsein der Zeit unüberwindliche Schranken setzten. Neben der bereits erwähnten providentiell zweckmäßigen Einordnung jedes Einzelphänomens an die ihm zukommende Stelle im Gesamtplan des Weltganzen steht das Axiom, nach dem die gesamte rezente Pflanzen- und Tierwelt bei der ursprünglichen Weltschöpfung entstanden sei, und als Folgerung daraus das Axiom einer Konstanz der seitdem existierenden Arten. Die all dem zugrundeliegende Prämisse, Gott habe bei der Schöpfung die gesamte Naturordnung auf alle Zeiten hin unwandelbar fest bestimmt, bildete den Angelpunkt des „großen deistischen Kompromisses“, der seit dem ausgehenden 17. Jahrhundert die relativ konfliktfreie Koexistenz der rationalen Naturforschung einerseits und der christlichen Theologie andererseits ermöglichte. ${ }^{88}$ Diese Axiome herrschten noch bis hin $\mathrm{zu}$ Darwin in kaum angefochtener Selbstverständlichkeit. Über diese absoluten Grundvoraussetzungen konnte seinerzeit niemand hinaussehen, sie bildeten den festen Rahmen jeglicher Erörterungen gerade über die Menschenrassen. Unsere Perspektive des Rückblicks aus der NachDarwinschen Naturanschauung macht es uns schwer, diese Vorstellungsweise nachzuvollziehen, aber wir müssen uns klar vor Augen halten, daß es in diesem Denken keinen Platz für eine weltimmanente Evolution der Lebewesen gab, geschweige denn für eine phylogenetische Verwandtschaft der Arten.

Diese selten im vollen Umfang ausdrücklich ausgesprochene, aber selbstverständlich feststehende Grundkonzeption, von der alles Nachdenken und Argumentieren ausging, ließ kaum eine plausible Erklärung des Tatbestands zu, um den es hier ging: die Existenz verschiedener Rassen, deren geographische Verteilung über die Erdoberfläche und die Möglichkeit ihrer Vermischung. In dieser Aporie findet Kant seine $\mathrm{Zu}-$ flucht bei einer äußerst gezwungenen Erklärung: auf Vorstellungen der Präformationstheorie zurückgreifend, nimmt er ,gewisse ursprüngliche in dem ersten und gemeinschaftlichen Menschenstamm auf die jetzt vorhandenen Rassenunterschiede ganz eigentlich angelegte Keime“ an, ${ }^{89}$ die sich erst später bei der Ausbreitung der Menschen über die verschie-

87 „Absolute presuppositions“ im Sinne von R. G. Collingwood: An Essay on Metaphysics. Ed. w. an Introduction by Rex Martin. Oxford: Oxford Univ. Press 1998. S. 21-33.

88 Die Formulierung „the great Deist compromise“ findet sich bei Stuart Hampshire: Spinoza and Spinozism. Oxford: Clarendon Press (2005), S. 44, wo auch die historischen Zusammenhänge näher erläutert werden. Vgl. Ernst Troeltsch: Der Deismus. In: Ernst Troeltsch: Gesammelte Schriften. Neudruck. Bd 4. Aalen: Scientia Verl. 1966. S. 429-487, bes. S. 440-442.

89 Kant Bd VI S. 77. 
denen Klimazonen ,gelegentlich, und diesem gemäß auch verschiedentlich, auswickelten“..$^{90}$ Hier erreicht also die „Zurüstung“991 der Natur ihre Verwirklichung erst nach einer Wanderung und im Verlauf mehrerer Generationen, und zwar auf verschiedene, dem jeweiligen Klima angemessene Weise. Sobald sich die vier Rassen in ihren ersten Wohnsitzen voll entwickelt hatten, haben weitere Verpflanzungen in andere Regionen den ursprünglichen Rassencharakter nicht weiter verändern können. Mit einigen beiläufigen Bemerkungen verrät Kant, daß ihm sehr wohl bewußt ist, auf welch gewagtes „Hypothesenspiel“"92 er sich hier eingelassen hat. Vor allem sieht er die von ihm postulierten Anlagen bedroht von Ockhams Rasiermesser, dem Verbot einer ungerechtfertigten Begriffsvermehrung. ${ }^{93}$

Was Forster an erster Stelle zum Widerspruch gegen Kant herausforderte, war dessen mit der offenkundigen Mißdeutung eines Reiseberichts begründete falsche Behauptung, „daß die Bewohner der meisten Inseln [der Südsee] Weiße sein müssen“". ${ }^{94}$ Kants Artikel kam Forster im entlegenen Wilna erst mit großer Verspätung zur Hand, ${ }^{95}$ aber als er ihn schließlich las, hatte er selbst gerade wenige Wochen zuvor im Vorwort seiner Halleschen Dissertation De plantis esculentis insularum oceani australis eine eingehende und umfassende, auf der eigenen direkten Erfahrung beruhende Gesamtcharakteristik der beiden Rassen des Pazifik geliefert (von diesem Text wird hier noch ausführlicher zu reden sein). ${ }^{96}$ So kann Forster mit Recht behaupten, „daß in Absicht der Südseeinsulaner alles geleistet worden ist, was man billiger Weise von den Beobachtern fordern konnte, ${ }^{\text {" } 97}$ und ist nur zu bescheiden, dabei auch auf seine eigene Leistung hinzuweisen; immerhin faßt er hier noch einmal seine Beschreibung dieser Rassen knapp zusammen. ${ }^{98}$ Jedenfalls hat er Grund zu der pikierten Umständlichkeit, mit der er den Philosophen über die gehörige Anerkennung unzweifelhaft bezeugter Erfahrungsdaten belehrt, und es lag auch nahe, daß er sich zur Widerlegung von Kants rein

90 Kant Bd VI S. 74.

91 Kant Bd VI S. 78.

92 Kant Bd VI S. 81.

93 Kant Bd VI S. 71 und 77; vgl. H. J. Cloeren: Ockham's razor. In: Historisches Wörterbuch der Philosophie. Hrsg. v. Joachim Ritter u. Karlfried Gründer. Bd 6. Basel/Stuttgart: Schwabe (1984). Sp. 1094-1096.

94 Kant Bd VI S. 67.

95 Vgl. AA VIII 130f., Uhlig 2004 S. 197, 201.

96 AA VI 95-103; zur Datierung vgl. die Briefzeugnisse in AA XIV 466, 472, 479, 482-484, 486.

97 AA VIII 136.

98 AA VIII $134 f$. 
spekulativer schematischer Einteilung der Rassen nach vier Farben vor allem auf die damals bereits wesentlich differenzierteren Erkenntnisse der völkerkundlichen Feldforschung in den verschiedenen Weltteilen beruft. Forster konstruiert zwar eine klimatisch bedingte, von Norden nach Süden hin fortschreitende „Farbenleiter" ${ }^{\text {"99 }}$ der Hautfärbung; aber diese bietet ihm mit ihren lokalen Variationen kein Kriterium zur Unterscheidung der Rassen. Dagegen findet er, auf Campers und Soemmerrings Untersuchungen gestützt, die wirklich charakteristischen Kennzeichen der Rassen vielmehr in anatomischen Zügen zumal des Schädelbaus wie dem Camperschen Gesichtswinkel. Auf Kants These von der Zweckdienlichkeit der Hautfarben unter verschiedenen Klimabedingungen geht Forster gar nicht ein. So mußte Kant in seiner Replik, die er 1788 unter dem Titel Über den Gebrauch teleologischer Prinzipien in der Philosophie veröffentlichte, bedauernd feststellen, er sei wider Erwarten nicht verstanden worden. ${ }^{100}$

Es wäre jedoch falsch, die Kontroverse zwischen den beiden auf den Gegensatz zwischen Empirie und Theorie zu reduzieren. Auch Forster war sich darüber klar, daß Erfahrungsdaten den Zusammenhang eines begrifflichen Rahmens erfordern. Aber er setzte diese beiden Komponenten des Wissens in eine historische Dimension und bemerkte eine vom Erkenntnisfortschritt bewirkte dialektische Spannung zwischen ihnen. Von klein auf hatte ihm sein unplanmäßiges Studium in der Gelehrtenwerkstatt seines Vaters vor Augen geführt, wie Entdeckungen und neue Forschungsergebnisse die Wissenschaften zur Revision ihrer Prinzipien zwangen, und im Verein mit Lichtenberg, Soemmerring, Camper und anderen lernte er später weitere Umwälzungen dieser Art in der Chemie der Gase, in der Elektrizitäts- und Wärmelehre, in der vergleichenden Anatomie und in anderen Disziplinen kennen. So konnte er fast die Thesen Thomas S. Kuhns über die Struktur wissenschaftlicher Revolutionen als Paradigmenwechsel ${ }^{101}$ vorwegnehmen, wenn er schrieb:

Nach gewissen angenommenen Sätzen, die er [Linné] aus seiner Erfahrung abstrahirt hatte, entwarf er sein Fachwerk, und paßte nun die Wesen der Natur hinein. Allein so lange unsere Erkenntniß mangelhaft bleibt, scheinen wir von einer Infallibilität der Principien noch weit entfernt zu seyn. Bestimmungen, die sich auf eingeschränkte Erkenntnis gründen, können zwar innerhalb dieser Schranken brauchbar seyn; aber sobald sich der Ge-

99 AA VIII 138.

100 Kant Bd V S. 140.

101 Thomas S. Kuhn: The Structure of Scientific Revolutions. Chicago: University of Chicago Press 1962. 
sichtskreis erweitert, der Sehepunkt verrückt, werden sie da nicht einseitig und halbwahr erscheinen? In der Litterargeschichte der Naturkunde giebt es hievon auffallende Beyspiele. Die Botanik, die Chymie und die Physik sind lediglich aus diesem Grunde jetzt ganz etwas anderes als vor funfzig Jahren. Vielleicht wird unser jetziges Schema der Wissenschaften ein halbes Jahrhundert weiter hinaus, eben so wie das vorige, veralten und mangelhaft werden. Sogar die spekulative Philosophie dürfte diesem allgemeinen Schicksal unterworfen seyn. Wer denkt hiebey nicht gleich an die Kritik der reinen Vernunft? ${ }^{102}$

Im Bewußtsein der ständig fortschreitenden Erforschung der Natur hatte Forster bereits die geologischen, geographischen, botanischen, zoologischen und anthropologischen Einsichten seiner Weltreise durchweg als rein tentative, vorläufige, ergänzungs- und korrekturbedürftige Beiträge vorgebracht, die nur als Bausteine für spätere umfassendere Theorien dienen sollten; er hütete sich ängstlich davor, sich voreilig auf unbewiesene „Systeme“ festzulegen oder gar selbst solche zu entwerfen. Schon in den methodischen Vorüberlegungen seiner Voyage Round the World hatte er gegen die Philosophen seiner Zeit polemisiert, die über willkürlich ausgewählten und verzerrten Erfahrungsdaten traumhaft-illusionäre theoretische Superstrukturen errichteten. Wenn er sich selbst auch ausdrücklich das Recht vorbehielt, aus seinen eigenen Beobachtungen jeweils allgemeine Schlüsse zu ziehen, die ihn wie ein Ariadnefaden zu weiteren Entdeckungen anleiten könnten, ${ }^{103}$ so sind doch seine Versuche, seine Erfahrungen zu deuten, oft begleitet von Vorbehalten wie dem folgenden:

These hints are submitted to the learned, whose province it is to confirm or refute them; but on which side soever the truth may fall, I shall rest equally contented, as I have adopted no particular system. ${ }^{104}$

102 AA VIII 132. Mit dem letzten Satz spielt Forster vielleicht auf die Vorrede zur 1. Auflage der Kritik der reinen Vernunft an, vgl. Kant Bd II S. 11-13.

103 AA I 13f., vgl. AA II 12f.

104 AA I 577, in der deutschen Übersetzung, AA III 326, fehlt diese Bemerkung ebenso wie die vorangehenden Vermutungen, auf die sie sich bezieht; weitere Beispiele: „Future observations [...] might perhaps lead to some more determinate conclusions;“ AA I 69, vgl. AA II 99; „Our experience should seem in some measure to contradict, and in some degree to confirm, this supposition.“ AA I 75, vgl. AA II 107; „Upon the whole, we were not fortunate enough to make any remarkable discoveries in regard to this phaenomenon; all our observations only tend to confirm the facts already noticed by others, and which are so largely commented upon by the learned Dr. Benjamin Franklin, F. R. S. His ingenious hypothesis, that whirlwinds and water-spouts have a common origin, has not been invalidated by our observations." AA I 123, vgl. 
In diesem Sinne räumte er später grundsätzlich der Hypothesenbildung eine eng begrenzte heuristische Funktion ein: als richtungweisende Anregungen für weitere Versuche und Beobachtungen können Hypothesen fruchtbar sein. Wenn der Naturforscher jedoch solche „Ausflüge in imaginäre Regionen“ übereilt und zu leichtgläubig ohne die Bestätigung durch empirisch bewiesene Forschungsergebnisse als evidente Wahrheit ansieht, wird er oft unter Zeitverlust und unter Aufgabe seiner vermeintlichen Erkenntnisse zur Rückkehr an seinen Ausgangspunkt gezwungen. ${ }^{105}$ Mit diesem Mißtrauen gegen ungeprüfte Hypothesen und der vorsichtig abwartenden Zurückhaltung gegenüber wissenschaftlichen

AA II 173; ,The singular custom, which forces the sexes to shun each others company at their meals, is already mentioned by former voyagers, who have been equally unsuccessful with ourselves in discovering its cause." AA I 171, vgl. AA II 240; ,What I have here said is sufficient to prove, that men in a similar state of civilization resemble each other more than we are aware of, even in the most opposite extremes of the world. I should be sorry to have made these slight remarks, if they should unfortunately lead some learned schemer on a wrong scent." AA I 402, vgl. AA III 85; ,[...] the custom must have some other origin among them, which a connected series of accurate observations may perhaps in time lead us to discover." AA I 423, vgl. AA III 116; „I have only ventured out into the great field of probabilities, and I am ready to quit my opinion as soon as another more just and more rational is offered." AA I 467, vgl. AA III 179.

105 „Physicus autem verus, idemque philosophus, licet aliquando excursionem sibi permittat in imaginarios regiones, licet hypotheses excogitet, easque conetur plausibiles et verisimillimas reddere, factisque, et experimentis congruas; tamen cavet sibi semper, ne pro veritate evidente, hypothesin habeat; et enim tantum scire et pro vero accipere profitetur, quantum cum summa evidentia sensibus suis demonstrari potest; supra ea, nihil omnino pro certo, et vero in physicis accipit, de cuius indole, experimenta nihil perdocent. Sic enim securo et certo in scientiis passu quamvis lento progreditur; e contra vero, si imaginariae hypothesi nimium confidat, saepe referre gradum, et redire unde processerit, compellitur, cum temporis et cognitionis jactura. Quid igitur est usus hypothesium, et num in totum forte rejiciendae? Non ego profecto is sum, qui humanum ingenium tam arctis camellis includat, ut nunquam ausit Verisimilia et possibilia sibi animo fingere; e contrario, hae hypotheses saepe physicos ad experimenta varii generis in corporibus naturalibus instituenda stimulant, qualia nunquam instituissent, nisi de veritate aut inanitate huius vel illius problematis soliciti fuissent. Hypothesis usus et finis ille debet esse, quod ad nova experimenta cum omni sollertia et ingenii acumine instituenda nos incitet, quod conciliat nobis habitum phaenomena, et observationes comparandi, combinandi, et ex iisdem proxima et evidentissima scholia, sive veras consequentias deducendi, quibus omnibus scientia indies magis magis firmetur, eiusque utilitas et ad humanae vitae necessitates adplicatio in universum multiplicetur." AA VI 1205. 
Theorien steht Forster fest in der methodischen Tradition der Londoner Royal Society, ${ }^{106}$ mit deren Arbeitsweise er bereits vor der Weltreise vertraut war und deren Mitglied er Anfang 1777 wurde. Ihren skeptischen Wahlspruch „Nullius in Verba“ stellte er seinem Essay Cook der Entdecker voran, wohl um hervorzuheben, daß Cooks Entdeckungen allgemein anerkannte aber ungegründete Theorien widerlegt hatten. Noch in den Ansichten vom Niederrhein mahnte er angesichts des Streits zwischen Plutonismus und Neptunismus, ,daß das nullius in verba nirgends unentbehrlicher ist, als im hypothetischen Theile der Naturgeschichte". ${ }^{107}$

Die allerletzten Sätze seiner Voyage Round the World setzten deren Neuentdeckungen einerseits selbstbewußt dem vorherigen Wissensstand entgegen, bezeichneten sie andererseits aber als unbedeutend angesichts der unermeßlichen Menge noch unbekannter Tatsachen, an denen der menschliche Geist sich in künftigen Zeitaltern mit weiteren Forschungen bewähren könne. ${ }^{108}$ In seiner Abhandlung über den Brotbaum bekannte Forster sich zur Rolle des Vorläufers eines „weiterschauenden Weltweisen", der

mit den Materialien, die wir sammeln, das große kaum noch gegründete Lehrgebäude der Physik vollendet haben wird. Ein Zaubernetz von unzähligen Fäden und durcheinandergeschürzten Knoten, wo Eins mit Allen und Alles mit Einem zusammenhängt, ein System voll himmlischer Uebereinstimmung wird er einst in der Mannigfaltigkeit der Schöpfung finden, wo unser begränzter Blick jetzt nur das Gaukeln einer unerschöpflichen Phantasie wahrzunehmen glaubt, die ihr Füllhorn auf gerathewohl ausgeschüttet hat. Wie frohen Muthes können wir da nicht künftigen Zeitaltern vorarbeiten, und auf die Früchte unsrer Bemühungen Verzicht thun, indem wir bereits so glücklich im Genuß der reichen Erndte sind, die eben so durch unserer Vorgänger Aussaat, uns bereitet ward. Wohlan! laßt uns willig die voreiligen Entstehungshypothesen in das enge Zimmer zurück bannen, wo sie vielleicht in finstern Rauchgewölken entstanden. Laßt uns die Natur in ihren entferntesten und verborgensten Werkstätten, wie in den nahen und zugänglichen, belauschen, nur Thatsachen aufzeichnen und denn behutsame Folgerungen ziehn. ${ }^{109}$

Forster relativierte so bescheiden sein eigenes Forschen historisch und stellte es in den Dienst eines künftigen Lehrgebäudes einer Biogeographie, das er selbst aus seiner beschränkten Perspektive noch nicht erah-

106 Vgl. John Gribbin: The Fellowship: Gilbert, Bacon, Harvey, Wren, Newton, and the Story of a Scientific Revolution. Woodstock \& New York: Overlook Press (2007). Bes. S. 183-189, 260, 267.

107 Vgl. Uhlig 2004 S. 28, 44, 75; AA V 191 und AA IX 16.

108 AA I 675, vgl. AA III 452.

109 AA VI 69f. 
nen konnte. Tatsächlich bot er damit eine prophetische Vorschau auf die Deszendenztheorie.

Aber diese zuversichtliche Erwartung fundamentaler Erweiterungen der Naturerkenntnis ließ ihn doch nicht die Schranken erkennen, mit denen sein ,jetziges Schema der Wissenschaften“ seinen eigenen Blick noch einengte. Vielmehr war auch er ausweglos befangen in derselben epistemischen Situation ${ }^{110}$ wie Kant, und seine Denkmöglichkeiten waren unentrinnbar begrenzt durch die erwähnten drei seinerzeit noch unhintergehbaren Suppositionen der Naturgeschichte: die Annahmen eines teleologisch geordneten Weltgefüges, der anfänglichen Schöpfung der gegenwärtig existierenden Lebewesen und der Konstanz der Arten.

In seiner Voyage Round the World hatte Forster wiederholt die genau ausgeklügelte Zweckmäßigkeit bestimmter Naturphänomene bewundert und entweder darin, in der physikotheologischen Tradition, ${ }^{111}$,the true ways of Divine Providence in the wonderful works of the creation" erkannt oder kurzerhand die Natur als Ursache dieser Ordnung bezeichnet. ${ }^{112}$ Auch in seinen Wilnaer Vorlesungen bedachte Forster wie-

$110 \mathrm{Zu}$ diesem Begriff vgl. Jürgen Habermas: Wahrheit und Rechtfertigung. Philosophische Aufsätze. Erw. Ausg. (Frankfurt am Main): Suhrkamp (2004). S. 4547, 50f.; vgl. Uhlig 2004 S. 202 f.

111 Vgl. Stefan Lorenz: Physikotheologie. In: Historisches Wörterbuch der Philosophie. Hrsg. v. Joachim Ritter u. Karlfried Gründer. Bd 7. Basel: Schwabe (1989). Sp. 948-955.

112 Hier nur einige Beispiele: Zur Anpassung der Pinguine an ihren Lebensraum: „Their very thick skin and their fat seem wisely appropriated to them by nature, to resist the perpetual winter of these unhospitable climates; their broad belly, the situation of their feet far behind, and their fins, which supply the place of wings, are constructed with equal wisdom to facilitate the progress of their otherwise lumpish bodies through the water." AA I 75, vgl. AA II 107. $\mathrm{Zu}$ Hunden als Schlachttieren: „Nature seems expressly to have intended them for this use“. AA I 145, vgl. AA II 204. Zur geographischen Verbreitung der Albatrosse: ,[...] so carefully has nature allotted to each animal its proper place of abode." AAI 278, vgl. AA II 382. Zur Entstehung der Südsee-Atolle aus den Kalkabscheidungen von Korallen: „Thus Providence, in its wise dispensations, made even these insignificant narrow ledges rich enough in the productions of nature, to supply a whole race of men with the necessaries of life. And here we cannot but express our admiration, that the minutest agents are subservient to the purposes of the Almighty Creator.“ AA I 368f., vgl. AA III 39. Zur Erklärung des geschlechtsspezifischen Unterschieds in der Färbung von Gänsen: „It should seem that nature hath very wisely ordered this disparity; [...] perhaps our understanding is much too short-sighted to assign, on such slight grounds, the true ways of Divine Providence in the wonderful works of the creation." AA I 614, vgl. AA III 378; in demselbem Sinne zitiert Forster angesichts eines Meeresleuchtens, das ihn zur Bewunderung des allmächtigen Schöpfers bewegte, 
derholt die harmonische Naturordnung, in der jeder Teil unentbehrlich ist. $^{113}$

Kant hatte, um seine genetische Artbestimmung gegen Linnés morphologische Klassifizierung abzusetzen, dessen Naturbeschreibung eine Naturgeschichte im engeren Sinn gegenübergestellt, ,in der es nur um die Erzeugung und den Abstamm zu tun ist" ". ${ }^{114}$ Aber dem hielt Forster entgegen, dies dürfte „,wohl nur eine Wissenschaft für Götter und nicht für Menschen seyn“, da menschliche Erfahrung nicht bis zum Beginn des Lebens zurückreiche. Er suchte die Unmöglichkeit solcher Erkenntnisse $\mathrm{zu}$ verdeutlichen durch eine Reihe von rhetorischen Fragen. Aber paradoxerweise verraten gerade diese Fragen mit ihren lebhaft anschaulichen Formulierungen, daß für Forster vor aller Erfahrung ein ganz bestimmtes Bild von der Entstehung des Lebens fraglos selbstverständlich feststeht: eine massenhafte Urzeugung, die alle Lebewesen aus dem schlammigen Erdboden hervorgehen läßt; seine Phantasie wird hier offenbar geleitet von der Analogie zum Pflanzenwuchs und von der Etymologie des Wortes ,autochthon“:

Wer hat die kreißende Erde betrachtet in jenem entfernten und ganz in Unbegreiflichkeit verschleyerten Zeitpunkt, da Thiere und Pflanzen ihrem Schoße in vieler Myriaden Mannigfaltigkeit entsproßen, ohne Zeugung von ihres Gleichen, ohne Samengehäuse, ohne Gebärmutter? Wer hat die Zahl ihrer ursprünglichen Gattungen, ihrer Autochthonen, gezählt? Wer

eine Stelle aus der Historia Naturalis von Plinius (AA I 49, vgl. AA II 74), mit der auch Linné programmatisch die Einleitung seiner Fauna svecica beschlossen hatte (Carolus Linnaeus: Fauna Svecica Sistens Animalia Svecicae Regni. Stockholmiae: Laurentius Salvius 1746. Praefatio). Von all dem sind die zahlreichen Gelegenheiten zu unterscheiden, wo Forsters persönliche Frömmigkeit das Gelingen der Expedition Cooks dankbar der ,tutelar guidance of Divine Providence" zuschreibt, z. B. AA I 20f., vgl. AA II 38f., AA I 73, vgl. AA II 104, AA I 84f., vgl. AA II 120f., AA I 124, vgl. AA II 174.

113 „Quod si a rerum necessitudine forte quis argutaretur, hominem ad mundi harmoniam necessarium, hoc ipso argumento pro fine creationis haberi posse: illi quidem libenter concedam, hominem ad perfectionem mundi necessarium fuisse, eadem lege qua muscas, et reliqua insecta, et minutissima animalcula infusoria non fortuitò sata, sed necessitate naturae exsistentia, certisque legibus cum ceteris rebus coniuncta, nihil autem in rerum natura supervacaneum esse, inficias iri nequit. At vero, hinc si colligere velim, mundum alicuius atomi caussa creatum fuisse, risum teneatis, auditores?“ AA VI 1039; „Ces deux usages des feuilles nous démontrent bien que la Nature s'est servi des plantes pour maintenir une liaison três étroite entre tout ce qui existe dans la Nature; et que tout se tient reciproquement dans ce monde, tellement qu'il n'y a pas un seul objet dont on puisse se passer, sans qu'il ait un défaut três sensible dans l'harmonie de l'univers." AA VI 1404.

114 Kant Bd VI S. 75, Anm., ausführlicher Kant Bd V S. 142-144. 
kann uns berichten, wie viele Einzelne von jeder Gestalt, in ganz verschiedenen Weltgegenden sich aus der gebärenden Mutter weichem, vom Meere befruchteten Schlamm organisirten? Wer ist so weise, der uns lehren könne, ob nur einmal, an einem Orte nur, oder $\mathrm{zu}$ ganz verschiedenen Zeiten, in ganz getrennten Welttheilen, so wie sie allmälig aus des Oceans Umarmung hervorgiengen, organische Kräfte sich regten? ${ }^{115}$

Von herkömmlichen Vorstellungen weicht dies höchstens dadurch ab, daß die Möglichkeit einer zeitlichen und örtlichen Ausdehnung des Schöpfungsvorgangs zugegeben wird und dieser selbst nicht als außerweltlicher Zugriff, sondern als immanenter Geburtsprozeß konzipiert ist.

Jedenfalls gilt auch für Forster die immerwährende Konstanz der Arten mit dogmatischer Strenge: in seinem Vortrag Ein Blick in das Ganze der Natur bekräftigt er sie, indem er die Arten (auch er spricht hier wie andernorts von „Gattungen“) mit Buffons Worten als die ,einzigen Wesen der Natur, der Natur an Alter und Dauer gleiche Kräfte" bezeichnet. ${ }^{116}$ Freilich wurde dieses Bild der Schöpfung in Frage gestellt durch die fossilen Reste ausgestorbener Tierarten, die damals allenthalben zutage gefördert wurden. ${ }^{117}$ Solche Funde wurden Forster persönlich nahegebracht durch zwei gelehrte Sendschreiben, die Christian Friedrich Michaelis und Johann Heinrich Merck an ihn richteten. ${ }^{118}$

115 AA VIII 143.

116 AA VIII 89; vgl.: ,[...] les espèces sont les seuls êtres da la Nature; êtres perpétuels, aussi anciens, aussi permanens qu'elle;" De la Nature. Seconde Vue. In: [Georges Louis Leclerc, Comte de Buffon]: Histoire naturelle, générale et particulière, avec la description du Cabinet du Roi. Tome 13ème. Paris: Imprimerie Royale 1765. S. j.

117 Vgl. Forsters Rezension des Sendschreibens von Alberto Fortis über versteinerte Knochen von Elefanten und andere Petrefakten (AA XI 109-111); der Autor nimmt, wie damals üblich, das Alter dieser Fossilien viel zu niedrig an und bestreitet überdies, daß die betreffenden Tierarten wirklich ausgestorben seien, was Forster bezweifelt und der Prüfung durch weitere Forschung anheimstellt.

118 Herr Stabsmedicus Michaelis an Herrn Prof. Forster, über das große unbekannte Thier in Nordamerika. In: Göttingisches Magazin der Wissenschaften und Litteratur. Jg 3, 1783, St. 6, S. 871-874, abgedruckt in AA XVIII 119f.; Johann Heinrich Merck: Troisième Lettre sur les Os Fossiles d'Éléphans et de Rhinocéros qui se trouvent en Allemagne et particulièrement dans le Pays de Hesse-Darmstadt. Adressée à Monsieur Forster. Darmstadt 1786. Titel nach Heinz Tobien: Johann Heinrich Merck und Samuel Thomas Soemmerring als Paläontologen im ausgehenden 18. Jahrhundert. In: Samuel Thomas Soemmerring und die Gelehrten der Goethezeit. Beiträge eines Symposions in Mainz vom 19. bis 21. Mai 1983. Hrsg. v. Gunter Mann, Franz Dumont. Stuttgart, New York: Gustav Fischer 1985. = Soemmerring-Forschungen I. S. 119-148, bes. 147. Leider hat Mercks schwer zugängliches Sendschreiben nicht seinen verdienten Platz unter den Briefen an Forster im 18. Band der Akade- 
Aber statt nach innerweltlichen Ursachen dieser Phänomene zu suchen, verstieg Forster sich zu einer höchst gekünstelten metaphysischen Konstruktion: ausgestorbene Tierarten waren für ihn Wirkungen von Formen oder Ideen, die ,in der Urkraft (Natur)“ ruhen und „nach gewissen vom Schöpfer bestimmten Gesetzen zu ihrer Zeit in Wirksamkeit gerathen“ konnten, aber ,jetzt auf unserer Erde sich nicht mehr individualiter wirksam erzeigen". ${ }^{119}$

Nur aus dem Zusammenhang der genannten drei Grundaxiome konnte sich das Postulat erheben, daß bei der Weltschöpfung notwendigerweise eine größere Anzahl von Individuen pflanzenfressender Tiere geschaffen worden sein mußte als von fleischfressenden, damit die ersteren nicht sofort von den Raubtieren ausgerottet wurden. Dies gibt Forster in seinem Aufsatz über die Menschenrassen zu bedenken, und er beruft sich dabei auf E. A. W. Zimmermann. ${ }^{120}$ Implizit ist dieser Gedanke jedoch bereits enthalten in dem Weltbild, das Forster im Geiste Buffons in seinem Vortrag Ein Blick in das Ganze der Natur zeichnet. Dort wird dem teleologisch geordneten Weltplan ein dynamisch bewegter Charakter verliehen, indem die Kräfte und Wesen der Natur in eine antagonistische Spannung zueinander gesetzt werden. Nach dem Prinzip des dritten Newtonschen Gesetzes, das jeder Wirkung eine Gegenwirkung gleicher Stärke zuordnet, ${ }^{121}$ erhält sich die harmonische Ordnung des Ganzen gerade dadurch, daß seine Elemente einander feindlich widerstreiten, dabei aber ein genau abgestimmtes Gleichgewicht zueinander einhalten. So besteht im Tierreich zwar ein Kriegszustand zwischen den Raubtieren und ihren Beutetieren, aber deren Arten werden trotz allen Verlusten durch kompensierende Vorkehrungen der Natur jeweils in einer überwiegenden Anzahl von Individuen am Leben erhalten. ${ }^{122}$ Aus solchen Überlegungen zieht Forster den Schluß, daß am Ursprung

mie-Ausgabe gefunden; ein Fragment von Forsters Dankbrief an Merck steht in AA XIV 542f.

119 AA VI $1763 f$.

120 AA VIII 150, vgl. E[berhard] A[ugust] W[ilhelm] Zimmermann: Geographische Geschichte des Menschen, und der allgemein verbreiteten vierfüßigen Thiere, mit einer hiezu gehörigen Zoologischen Weltcharte. Leipzig: Weygand 1783. Bd 3, S. $202 f$.

121 AA VIII 82-85; vgl.: „Actioni contrariam semper \& aequalem esse reactionem: sive corporum duorum actiones in se mutuo semper esse aequales \& in partes contrarias dirigi." In: Isaac Newton: Philosophiae naturalis principia mathematica. The 3rd ed. (1726) with variant readings, assembled and ed. by Alexandre Koyré and I. Bernard Cohen, with the assistance of Anne Whitman. Vol. 1. Harvard Univ. Press 1972. S. 55.

122 AA VIII $93 f$. 
der Welt keineswegs nur ein einziges Paar von jeder Art erschaffen wurde. Dies steht nicht einmal im Widerspruch zur Bibel, die lediglich beim Menschen ein einziges Stammpaar festsetzt. Noch in seiner Göttinger Akademierede vom 18. September 1787 konnte sich Forster ausdrücklich auf die mosaische Erzählung von der Schöpfung der Pflanzen berufen, als er behauptete, ,die gesamte Erdoberfläche habe einst, nach dem Willen des Schöpfers der Natur, von selbst überall gleichzeitig mehrere Individuen vom Stamm jeder Art hervorgebracht" ${ }^{123}$

Ketzerei kam in solche Erwägungen erst, wenn man diese Vorstellung so generalisierte, daß auch beim Menschen eine Schöpfung mehrerer Paare angenommen wurde. Innerhalb der Schranken der oben umrissenen Axiome war auf diese Weise die Entstehung verschiedener Menschenrassen einigermaßen widerspruchsfrei zu erklären. Mit einer ausführlichen Darlegung dieses Gedankens, allerdings zugleich auch mit den religiösen Bedenken, die sich dagegen erhoben, wurde Forster bereits bekannt, als er von seiner Weltreise zurückkehrte und in England die Sketches of the History of Man von Henry Home, Lord Kames, kennenlernte, die dort 1774 erschienen waren und weithin Beachtung und Kritik gefunden hatten. Forsters intensive Lektüre dieses Werkes hinterließ deutlich sichtbare Spuren in seiner Voyage Round the World. ${ }^{124}$ Homes erster "Sketch" behandelt die Rassenunterschiede und deren Ursachen. Dabei widerlegt er die Behauptungen Buffons und Montesquieus, die Eigenheiten der Rassen seien auf Einwirkungen des Klimas zurückzufuihren, und sieht als einzige sinnvolle Alternative die Annahme einer Schöpfung mehrerer verschiedener, an jeweils bestimmte Klimate angepaßter Menschenpaare. Er beschließt jedoch seine Erörterung folgendermaßen:

Upon summing up the whole particulars mentioned above, would one hesitate a moment to adopt the following opinion, were there no counterbalancing evidence, namely, „That God created many pairs of the

123 „Quae cum ita sint, in eorum castra lubens me recipio, qui vetustissima traditione acceptam sententiam, experientiae consentaneam tuentur, cuncta, scilicet, cum staminum organicorum plena essent, superficiem telluris, nullo non in loco, stirpium vniuscuiusque speciei plurima simul indiuidua, moliente id naturae numine, olim sponte peperisse." Hier verweist eine Anmerkung auf 1. Mose 1, 11: „Und Gott sprach: Es lasse die Erde aufgehen Gras und Kraut, das sich besame, und fruchtbare Bäume, da ein jeglicher nach seiner Art Frucht trage und habe seinen eigenen Samen bei sich selbst auf Erden. Und es geschah also." AA VI 205.

124 Vgl. Ludwig Uhlig: Theoretical or Conjectural History. Georg Forsters Voyage Round the World im zeitgenössischen Kontext. In: Germanisch-Romanische Monatsschrift. 53, 2003. S. 399-414; Uhlig 2004 S. 86-93. 
human race, differing from each other both externally and internally; that he fitted these pairs for different climates, and placed each pair in its proper climate; that the peculiarities of the original pairs were preserved entire in their descendents; who, having no assistance but their natural talents, were left to gather knowledge from experience, and in particular were left (each tribe) to form a language for itself; that signs were sufficient for the original pairs, without any language but what nature suggests; and that a language was formed gradually, as a tribe increased in numbers and in different occupations, to make speech necessary"? But this opinion, however plausible, we are not permitted to adopt; being taught a different lesson by revelation, namely, That God created but a single pair of the human species. Though we cannot doubt of the authority of Moses, yet his account of the creation of man is not a little puzzling, as it seems to contradict every one of the facts mentioned above.

Aus Respekt vor der Autorität der biblischen Offenbarung verbietet sich Home also, die logische Konsequenz aus seinen Erwägungen zu ziehen. Einen Ausweg aus diesem Dilemma findet Home in einer anderen Episode der biblischen Geschichte: die Zerstreuung der Völker nach dem Turmbau zu Babel habe eine Entartung und Verwilderung bewirkt, in der sich die Menschen jeweils an ihre verschiedenen Wohnorte und Klimate anpaßten. ${ }^{125}$

125 Henry Home, Lord Kames: Sketches of the History of Man. Considerably Enlarged by the Last Additions and Corrections of the Author. Ed. and with an Introduction by James A. Harris. Book I-III. Indianapolis: Liberty Fund (2007). Bd I S. 47f. Mit einer Inkonsequenz, in die Home nicht selten verfällt, erwähnt er an einer anderen Stelle seines Buchs allerdings doch die „local creation“ als unvermeidliche Annahme (ebda. Bd II S. 560). Van Hoorn 2004 S. 93-96, 166f., 175, nennt Home als Vorgänger Forsters mit seiner Annahme einer ursprünglichen Schöpfung verschiedener klimatisch angepaßter Rassen, sie verschweigt jedoch, daß Homes religiöse Skrupel ihn vor diesem Konzept zurückschrecken ließen. Erst recht unbegreiflich ist es, daß van Hoorn es unterläßt, im Zusammenhang mit Forsters Beschreibung seiner Weltreise Homes Sketches überhaupt nur zu erwähnen. Allein die gebührende Berücksichtigung des Verhältnisses zwischen diesen beiden Werken widerlegt van Hoorns These, Forster habe seine Reise „,noch ganz im Banne Buffons“ angetreten und ,sich im Verlaufe seiner Weltumseglung und ihrem schriftlichen Nachvollzug von einer unreflektierten Anwendung der Klimatheorie entfernt" (van Hoorn 2004 S. 39). Diese These stützt van Hoorn auf wenige willkürlich herausgegriffene und künstlich isolierte Aussagen über Hautfarbe und körperliche Merkmale der Eingeborenen, während sie Forsters Erörterung von Völkerwanderungen und Sprachverwandtschaften beiseite schiebt (van Hoorn 2004 S. 80 und 81, Anm. 214) und überhaupt die Fülle von Zeugnissen sowohl in Georg Forsters Voyage wie auch in J. R. Forsters Observations außer acht läßt, in denen sich die wesentlich umsichtigeren und differenzierteren Bemühungen der beiden um Charakterisierung und Vergleich der Inselvölker niederschlagen. $\mathrm{Zu}$ bemerken ist 
Offenbar unter dem Eindruck von Homes Argumentation hält Forster in seiner Voyage Round the World betont skeptischen Abstand gegenüber Buffons Erklärung der Hautfarbe durch das Klima. ${ }^{126}$ Was die Schöpfung mehrerer Menschenpaare anging, so teilte Forster, dessen traditioneller Glaube an die biblische Offenbarung damals noch unangefochten war, ${ }^{127}$ sicher Homes Bedenken dagegen. Diese Frage kommt allerdings in der Voyage gar nicht auf; hier werden nämlich nicht etwa uranfängliche Rassenunterschiede und ihre Ursachen erörtert, vielmehr werden nur von Fall zu Fall die Eigenheiten einzelner Völker beschrieben und miteinander verglichen. Die physische Erscheinung wird dabei wohl einbezogen, jedoch nur als Teilaspekt. Viel wichtigere Elemente der Gesamtcharakteristik eines Volksstamms sind dessen Lebenskultur und vor allem dessen Sprache. Ähnlichkeiten in diesen Bereichen beweisen eine gemeinsame Herkunft der verschiedenen und weit verstreuten Völker. ${ }^{128}$ Das aus weiter Ferne und ohne Aussicht auf baldigen

überhaupt, daß Forsters Voyage Round the World nicht einen ,schriftlichen Nachvollzug“ der Weltreise bietet, sondern eine Darstellung aus der Perspektive des rückblickenden Teilnehmers, der seine Erfahrungen nachträglich zu verarbeiten und im Lichte der zeitgenössischen Literatur zu deuten sucht.

126 „But whether, according to his and the Abbé de Manet's opinion, this change of complexion was effected merely by the heat of the torrid zone, or whether they have acquired their sable colour by intermarriages with negroes from the adjacent coast of Africa, is a question which I do not venture to decide, though so able and judicious an investigator of nature as Count Buffon, asserts, that 'the colours of the human species depend principally on the climate." " AAI 37, vgl. AA II 59; „If the influence of climate be admitted, which is so strongly defended by Count Buffon, it offers another proof that Mallicollo has been but lately peopled, since the interval of time has not been sufficient to work a change in the colour and hair of the inhabitants. But I am far from being convinced of this general and powerful influence of climates." AA I 467, vgl. AA III 179.

127 Vgl. Uhlig 2004 S. 92.

128 Hier nur einige Beispiele: „The language of these people, and their customs, are therefore still unknown, and these are the only circumstances from which the origin of nations, who have no records among them, can be traced." AA I 153, vgl. AA II 215; ,It appeared, upon the whole, that the customs and language of these islanders have a great affinity with those of the Taheitians, and that it would not therefore be very singular to find a coincidence even in their amusements. The greatest differences between these two tribes, who must have originated from the same stock, seem to be owing to the different nature of their islands.“ AA I 274, vgl. AA II 376; „Be this as it may, so much seems to be certain, that their systems of politics and religion, from their similarity with the Taheitians, as far as we could judge, must have had one common origin, perhaps in the mother country, from whence both these colonies issued. [...] The affinity of their languages is still more decisive." AA I 276, vgl. AA II 
Erfolg anvisierte Ziel dieser Forschungen ist eine Rekonstruktion der Siedlungsgeschichte der Südsee. Forster ist sich der Vorläufigkeit und Unvollständigkeit seiner Bemühungen vollauf bewußt, er muß zugeben, „that the history of the human species in the South Seas cannot yet be unravelled with any degree of precision“. ${ }^{129}$ Er hütet sich auch ängstlich vor der Versuchung, spekulative Stammbäume zwischen verschiedenen Völkern zu konstruieren, wofür John Needham und Joseph de Guignes abschreckende Beispiele boten. ${ }^{130}$ Aber sowohl seine eigenen Beobachtungen auf den Inseln wie die Berichte früherer Forscher lassen ihn eindeutig eine Verwandtschaft aller Völker zwischen Neuseeland, den Freundschafts- und den Gesellschaftsinseln, den Marquesas und der Osterinsel erkennen. ${ }^{131}$ Für den davon grundverschiedenen Menschenstamm der Neuen Hebriden, zumal die hier bereits erwähnten Einwohner von Mallicolo mit ihren affenähnlichen Schädeln, erschließt Forster aus Gestalt, Sprache und Sitten eine Abstammung aus Neuguinea und

378f.; „In this, as in numberless other circumstances, they agree with the tribes who inhabit New Zealand, the Friendly and the Society Islands, and who seem to have had one common origin with them." AA I 342, vgl. AA II 462; ,, The natives of these different islands [the Marquesas], we have great reason to believe, are all of one and the same tribe, like the people of Taheitee and the Society Isles;“ AA I 362, vgl. AA III 31; „This behaviour, their manners, their beautiful forms, their dresses, provisions, embarkations, and their language, prove that they have the same origin with the Taheitians, and only differ from them in a few respects, which the nature of their country required." AA I 363, vgl. AA III 31; „It appears, from the accounts of former voyagers, that between the meridians of $170^{\circ}$ east from Greenwich, and $180^{\circ}$, there is a great number of islands, from the 10 th to the $22 \mathrm{~d}$ degree of latitude; all which, as far as they are known, seem to be inhabited by one race of people, who speak the same dialect of the South Sea tongue, and have the same social and mercantile disposition. All these then might be added to the Friendly Islands." AA I 447, vgl. AA III 151.

129 AA I 549, vgl. AA III 292.

130 ,The itch of tracing the pedigree of nations has lately made such havock in history, by endeavouring to combine the Egyptians and Chinese, that the learned must sincerely wish, it may never become a contagious distemper." AA I 402, vgl. AA III 85.

131 Vgl. AA I 276, 342-344, 358-363, vgl. AA II 379, 462-464, AA III 26-31 . 
Papua ${ }^{132}$ wenn er auch angesichts der mangelnden Kenntnis dieser Länder und ihrer Einwohner seine Unsicherheit eingesteht. ${ }^{133}$

Das Hauptkriterium für alle diese Vermutungen lieferten die jeweiligen Sprachen, die Georg Forster und sein Vater aufmerksam untersuchten. Georg Forster gibt davon in seiner Voyage nur einzelne Beispiele mit summarischen Hinweisen, ${ }^{134}$ und dies entspricht wohl seiner untergeordneten Rolle in diesen Beobachtungen bei der Arbeitsteilung mit seinem Vater. Johann Reinhold Forster war offenbar federführend in der methodischen linguistischen Forschung, und er behielt auch sich selbst die Veröffentlichung des eindrucksvollen Gesamtergebnisses dieser Arbeiten vor: in seinen Observations bietet er eine große Tafel mit Listen des Grundwortschatzes der besuchten Völker im Pazifik und anderer bereits bekannter Sprachen aus benachbarten Weltteilen zum Vergleich. Trotz aller Zurückhaltung angesichts der Lücken und Unsicherheiten seiner Daten findet er in ihnen das Zeugnis von zwei deutlich verschiedenen Sprachfamilien, und dies gibt ihm den endgültigen Beweis dafür, daß die Südsee von zwei Seiten her besiedelt wurde, einerseits von Nordwesten her durch die hellhäutigen Polynesier und andererseits von Westen her durch die dunkleren heute als Melanesier bekannten Stämme:

Allein ich kann mich hier des Gedankens nicht erwehren, daß jene in allen ebengenannten Sprachen vorkommende gemeinschaftliche Wörter, die Ueberbleibsel einer älteren und allgemeinern Sprache seyn können, welche, erst in der Folge der Zeiten, in so weit abweichende Mundarten zerfallen ist. Dem sey nun wie ihm wolle, so beweiset die Verwandtschaft der Sprachen hier wenigstens zur Genüge, daß die östlicheren Inseln im Südmeere von den östlich-asiatischen Eilanden her, sind bevölkert worden, die westwärts gelegenen Südseeinseln hingegen, ihre ersten Bewohner aus der Nähe von Neuguinea erhalten haben. Wären die Wörterbücher, aller der verschiedenen hieher gehörigen Sprachen vollständiger, so hätte man vielleicht den Ursprung der beyden südländischen Rassen, noch bestimmter von einzelnen asiatischen Stämmen herleiten können. Allein, gerade in diesem Fache findet man die größten Lücken. In der angehängten Tabelle

132 „So much is certain, that they appear to be of a race totally distinct from these. Their form, their language, and their manners strongly and completely mark the difference. The natives on some parts of New Guinea and Papua seem to correspond in many particulars with what we have observed among the Mallicollese." AA I 467, vgl. AA III 179.

133 „New Guinea and the islands adjacent, the only countries from whence we can expect some light on this subject, still remain unknown to us, not only in regard to their geographical situation, but more especially as to their inhabitants." AA I 467, vgl. AA III 179f.

134 Z. B. AA I 276, vgl. AA II 379; AA I 457, vgl. AA III 165 . 
habe ich die verschiedenen Sprachen, sowohl der von uns besuchten Inseln, als der gegen Osten und Westen angränzenden Völker mitgetheilt, um dem Leser die allgemeine Uebersicht zu erleichtern. ${ }^{135}$

Mit Hilfe dieser Vorstellung von der Besiedlung der Südsee erklärt auch Georg Forsters Monographie über den Brotbaum dessen Ausbreitung und Veredlung von der wilden Urform auf den Großen Sunda-Inseln bis zur samenlosen Kulturform Polynesiens: Analog zu den westasiatischen und den europäischen Völkerwanderungen setzt Forster „,bey dem asiatischen Stammvolke unserer Insulaner eine Wanderungsepoche“ voraus, in der ,ein vorhergefaßter Entschluß ostwärts zu wandern, Zurüstungen zur Reise möglich und nothwendig“ machte und der Brotbaum ,als das kostbarste, was wandernde Völker mit sich führen konnten, auf diese Art nach den östlichen Inselgruppen“" kam. ${ }^{136}$

Auch Georg Forsters bereits erwähnter Überblick über die Völker der Südsee in seiner Halleschen Dissertation De plantis esculentis insularum oceani australis geht aus von Johann Reinhold Forsters Unterscheidung der beiden Südsee-Rassen und ihrer Herkunft von den malaiischen Inseln einerseits und Papua und Neuguinea andererseits. Beide Rassen werden hier als distinkte und historisch wie geographisch fest umrissene Gesamtphänomene vorgestellt, wenn auch ihre verstreuten Stämme jeweils besondere Eigenheiten zeigen, die auf verschiedene Nahrungsund Lebensweisen zurückzuführen sind. ${ }^{137}$ Wie schon gesagt, rekapitulierte Forster diesen Befund, mit polemischer Wendung gegen Kants falsche Bezeichnung der Südsee-Insulaner als Weiße, in seinem Aufsatz Noch etwas über die Menschenraßen. ${ }^{138}$ Aber in der Dissertation fixiert er seinen Blick auf den physischen Unterschied zwischen den Rassen und

135 Hier wird Georg Forsters Übersetzung angeführt (J. R. Forster 1783 S. 253f.), die den englischen Originaltext (J. R. Forster 1996. S. 190) durch leichte Kürzungen deutlicher macht; vgl. Karl H. Rensch: Forster's Polynesian Linguistics. In: J. R. Forster 1996 S. 383-400; sowie Karl H. Rensch: Wegbereiter der historisch-vergleichenden Sprachwissenschaft: Reinhold und Georg Forster als Erforscher der Sprachen des Pazifiks auf der zweiten Reise von Cook 1772-1775. In: Georg-Forster-Studien, hrsg. im Auftr. d. Georg-Forster-Gesellschaft v. Horst Dippel u. Helmut Scheuer. Kassel: Kassel Univ. Pr. Bd. 3. (1999). S. 221-243; Renschs eingehende Arbeiten werden ignoriert von dem weit hinter ihnen zurückbleibenden Artikel von Yves Gilli: Der linguistische Beitrag in Georg Forster Reise um die Welt. In: Georg-Forster-Studien, hrsg. im Auftr. d. Georg-Forster-Gesellschaft v. Horst Dippel u. Helmut Scheuer. Kassel: Kassel Univ. Pr. Bd. 11. (2006). S. 89-110.

136 AA VI 66f., vgl. Uhlig 2004 S. 156f.

137 Vgl. Uhlig 1965 S. 58 und Uhlig 2004 S. 198-200.

138 AA VIII 134. 
leitet diesen aus einer ,ursprünglichen Verschiedenheit autochthoner Urvölker“ ab, „da diesen Menschenstämmen eine eigene unzerstörbare und gleichsam eingebrannte Form anhaftet, erkennbar an mehreren charakteristischen Kennzeichen, " die weder durch das Klima noch durch die Nahrung beeinflußt werden kann und sich, so lange keine Rassenmischung eintritt, in der Generationenfolge völlig unverändert bis auf die äußersten Nachkommen fortpflanzt. ${ }^{139} \mathrm{Er}$ faßt seine Meinung so zusammen:

Die größte organische Verschiedenheit zwischen den Menschenstämmen ist aus einer eigenen Prägung der Erzeugung abzuleiten; die eigentümlichen Sitten und beständigen Gewohnheiten entstehen aus der Nachahmung der Vorfahren; ein gewisser Einfluß des Klimas auf die Mentalität ist aber nicht ganz auszuschließen. ${ }^{40}$

Damit deutete Forster zum ersten Mal die Vorstellung einer polyphyletischen Herkunft der Menschheit an. Dazu hatte ihn die Abhandlung Ueber die körperliche Verschiedenheit des Negers vom Europäer ermutigt, die sein Freund Soemmerring ihm soeben gewidmet hatte und deren Ergebnisse er nun als Analogie zur Bestätigung seiner eigenen Annahme einer getrennten Abstammung der Südseerassen anführen konnte. Hatte Soemmerring allerdings noch an ,einem gemeinschaftlichen Stammvater" aller Menschen festgehalten, ${ }^{141}$ so behauptete Forster dagegen, die Entstehung der Rassen entziehe sich der menschlichen Erkenntnis, zumal da sie aller historischen Überlieferung vorausliege. Mit distanzierender Ironie schob er ausdrücklich die ,jüdischen Orakel, denen die Europäer aus Gewohnheit fromm anhängen“, beiseite, da auch diese nichts

139 ,Singularem hanc diversitatem inter Austrasiae vel Polynesiae populos, cum iam neque aëris, qui omnibus idem propemodum est, neque alimentorum, quibus omnes fere iisdem vescuntur, diversae qualitati tribuenda sit, originem ducere a primitiva autochthonum varietate arbitror. Indelebilis enim et tanquam inusta species, diversis hominum familiis inhaeret, plurimis notis characteristicis insignis, quae et climati omnimodo resistit, et ciborum commutatione non frangitur, nec non perpetua successione, nisi contaminatae fuerint generationes aliqua mixtela, a parentibus ad ultimam prolem integra meracissimaque descendit.“ AA VI 96.

140, „Equidem mihi videor illorum opinionem recte amplexum [!] esse, qui maximam inter hominum familias diversitatem organicam, ab ipso generationis typo derivandam, morumque notas characteristicas, et consuetudinum perpetuitatem imitatione maiorum oriundam existimant; climati tamen aliquid virium inesse ad inflectendos animos non omnino recusant." AA VI 102.

141 S. Th. Sömmerring [sic!]: Ueber die körperliche Verschiedenheit des Negers vom Europäer. Frankfurt, Mainz 1785. S. XX. 
über Rassenunterschiede aussagen. ${ }^{142} \mathrm{Daß}$ Forster hier ausdrücklich die jüdische Herkunft des Alten Testaments betonte, ist wohl ein Nachhall der religionskritischen Philosophischen Betrachtung über Theologie und Religion überhaupt, und über die jüdische insonderheit von Johann Heinrich Schulz, die Forster gerade im März 1786 mit Beifall las; das Werk des märkischen „Zopfpredigers“ bestärkte ihn endgültig in seiner Abkehr vom Kirchenglauben. ${ }^{143}$ Dieser erste öffentliche Angriff Forsters auf die Autorität der Bibel war seiner Sprache und Publikationsweise halber nur einem eng begrenzten akademischen Publikum zugänglich; immerhin nahm Blumenbach daran Anstoß, wie Forster verspätet und auf Umwegen erfahren sollte. ${ }^{144}$

Kurz darauf kam Forster der Gedanke der polyphyletischen Abstammung in seiner Auseinandersetzung mit Kant zustatten, als es darum ging, das offenbar schwächste Argument für dessen Rassentheorie anzugreifen. Dies war die Annahme einer Wanderung und Ausbreitung der Menschen, bevor sich in ihnen, dem jeweiligen Klima gemäß, die verschiedenen keimhaft angelegten Rasseneigenheiten entwickelten, die danach von keiner weiteren Klimaveränderung abgewandelt werden konnten. Es machte Forster sichtlich Vergnügen, die Widersprüche aufzuweisen, in denen sich der Philosoph hier ,seiner Theorie zu Gefallen“ verfing. ${ }^{145}$ Demgegenüber schien Forster eine „lokale Entstehung“ der Rassen immerhin eine plausiblere Lösung zu sein:

Die Natur hat vielmehr, wie Herr K[ant] selbst behauptet, einem jeden Stamme seinen Charakter, seine besondere Organisation, ursprünglich in Beziehung auf sein Klima und zur Angemessenheit mit demselben, gegeben. Unstreitig läßt sich dieses genaue Verhältniß zwischen dem Lande und seinen Bewohnern am leichtesten und kürzesten durch die lokale Entstehung der letztern erklären. ${ }^{146}$

Freilich ging es Forster bei diesem Vorschlag nicht bloß darum, die Theorie Kants mit ihren Widersprüchen und Komplikationen durch ein einleuchtendes Argument schlagend zu widerlegen. Vielmehr hatte dieser Gedanke für Forster den besonderen Reiz, daß er damit seine eigene Befreiung von der religiösen Bevormundung seines Denkens provozie-

142 „Attamen de origine harum in genere humano varietatum aliquid certi vel ea ratione constitui nequit, quod in universum historica traditione antiquiores sint, et Iudaeorum oracula, quibus Europaei e consuetudine piè assentiuntur, de iisdem sileant." AA VI 97.

143 Vgl. AA XIV 447, 454, und Uhlig 2004 S. 196.

144 Vgl. Uhlig 2004 S. 204f.; AA XIV 582f., 588, 635.

145 AA VIII 150.

146 AA VIII 151. 
rend an die Öffentlichkeit bringen konnte. Mit dieser Absicht richtete er seine Polemik auch noch gegen einen weiteren Artikel Kants, den Mutmaßlichen Anfang der Menschengeschichte. Ähnliche Überlegungen hatte Voltaire dazu benutzt, die biblische Schöpfungsgeschichte der Absurdität zu überführen, und Forster machte sich nun lustig über die verbreitete Berührungsangst vor diesem Ketzer. War er sich auch der Gefahr bewußt, daß diese These zur Rechtfertigung der Rassendiskriminierung und Versklavung der Afrikaner mißbraucht werden konnte, so konnte er darauf hinweisen, daß bisher die gegenteilige Annahme einer gemeinsamen Abstammung eine solche Erniedrigung, wie überhaupt Blutvergießen und Kriege auch nicht verhindert habe.

Von all dem abgesehen, gab die Debatte über die Menschenrassen Forster einen Anlaß zur prinzipiellen Erörterung der Taxonomie. Dies war kein neues Thema für ihn. Vom Anfang seiner botanischen Arbeiten an mit dem Linnéschen System vertraut, hatte er auch dessen Grenzen und Schwächen bemerkt, und gerade bevor er seinen Aufsatz schrieb, hatten ihn Campers vergleichende Anatomie und Herders Ideen zur Philosophie der Geschichte der Menschheit mit der Vorstellung einer nicht-systematischen Naturordnung bekannt gemacht. Aber Kant griff das Linnésche System von einer ganz anderen Seite her an, indem er diesem bloß nach Ähnlichkeiten klassifizierenden Schulsystem eine „Natureinteilung“ entgegensetzte, ,welche die Tiere nach Verwandtschaften in Ansehung der Erzeugung einteilt". Für ihn war eine Gattung (so gab auch Kant hier, wie oben bemerkt, den systematischen Terminus ,species" wieder) eine Gruppe von Lebewesen gemeinsamer Abstammung, und, einer Regel Buffons folgend, sah er den Beweis für diese Gemeinsamkeit in dem Vermögen, ,mit einander fruchtbare Jungen zu erzeugen “ ${ }^{147}$ Diese genetische Definition einer Art forderte Forsters heftigen Widerspruch heraus: einerseits hielt er die gemeinsame Abstammung für prinzipiell unbeweisbar, und andererseits konnte er zahlreiche Beispiele von Bastardbildungen anführen, mit denen die Fortpflanzungsfähigkeit nachweislich die Grenzen einzelner Arten überschritt. Hier besann sich Forster auf den eingestanden künstlichen, nominalistischen Charakter von Linnés System, das die Naturwesen rein morphologisch zu beschreiben und zu klassifizieren suchte, ohne den Anspruch zu erheben, damit genetische Zusammenhänge festzustellen. Allerdings fand Forster dabei keine befriedigende Antwort auf die Frage, ob die verschiedenen Menschenrassen als Varietäten oder Arten anzusehen waren, wenn er nämlich nach Linnés Vorschrift eine Varietät „,blos durch die Unbeständigkeit ihrer Merkmale“ bestimmte, was auf die Rassen offensichtlich

147 Kant Bd VI S. 11, vgl. Kant Bd VI S. 78. 
nicht zutraf. ${ }^{148}$ Das Wort Rasse erschien Forster überhaupt im Sprachgebrauch zu unbestimmt und vieldeutig, ${ }^{149}$ so daß er meinte, man könne „es füglich entbehren“. 150

Über diesen scheinbar untergeordneten Einzelpunkt muß Forster nach Abschluß seines Menschenrassenartikels weiter nachgedacht haben, denn schon im Kompendium seiner zoologischen Vorlesung führt er nun eine völlig neue taxonomische Kategorie in die Systematik ein: das „exemplum“, das eigens mit der Absicht konzipiert zu sein scheint, den Rassen eine angemessene Stelle im Natursystem einzuräumen, nämlich innerhalb der Art und neben der Varietät. Als „exempla“ definiert Forster Gruppen von Tieren, die zu geringfügig von anderen abweichen, um eine eigene Art zu bilden, die sich aber von Varietäten in zwei Punkten unterscheiden: sie pflanzen ihre Eigenart unverändert fort, und es steht nicht fest, ob sie mit der übergeordneten Art einen gemeinsamen Ursprung haben. ${ }^{151}$ Das ungewöhnliche Wort „exemplum“ wählt Forster offenbar mit Bedacht, um die Unbestimmtheit des Wortes „Ras$\mathrm{se}^{\text {" }}$ und seiner naheliegenden lateinischen Äquivalente, wie ,gens“, „stirps“ oder „indoles“, zu vermeiden.

Damit sind wir, nach weit ausholenden Präliminarien, endlich zu unserem Text zurückgekehrt. In diesem läßt Forster die Auseinandersetzung mit Kant und die meisten ihrer Streitpunkte, wie die Erörterung der Hautfarbe, hinter sich; er verschweigt sogar Kants Namen und geht auch mit keinem Wort auf die biblische Schöpfungsgeschichte ein. Aber er zieht aus dieser Debatte nun eine nüchterne Bilanz, die seine eigene Position richtigstellt und klärt. Noch entschiedener als in dem Aufsatz über die Menschenrassen schließt er jetzt von der Definition einer Art jede genetische Begründung aus, wie die Annahme der gemeinsamen Abstammung oder Fortpflanzungsfähigkeit, und erkennt ausschließlich die Kriterien der deskriptiven Morphologie Linnés an, die eine Art rein durch die Gemeinsamkeit der charakteristischen Kennzeichen be-

148 AA VIII 146.

149 Diese Mehrdeutigkeit bestätigt übrigens sein eigener Gebrauch des Wortes „race“ und seiner Synonyme wie ,nation“, „people“, „tribe“, „stock“ und dergl. in seiner Voyage Round the World.

150 AA VIII 152.

151 „Minoris notae differentiae, quales coloris, magnitudinis, pubescentiae, cet. ad species distinguendas non valent. Exempla tamen specierum his notis ab invicem discrepantia [im Druck: discrepantium], quae in generatione continua persistunt, et de quibus non constat, quin communem ab unica specie [im Druck: species] originem trahant, a Varietatibus $(\mathbb{S}$. 10) inconstantibus, et procul dubio derivativis, cauté distinguenda sunt." AA VI $1480 \mathrm{f}$. 
stimmt. ${ }^{152}$ So unterscheidet er den Menschen vom Affen im Hinblick auf seine Anatomie als eine eigene Art (,species“), und auf Grund seiner geistigen Fähigkeiten trennt er ihn noch weiter von den Säugetieren insgesamt, indem er ihm sogar eine Gattung (,genus") für sich allein zuteilt. Für die Argumentationen, die dabei ins Spiel kommen, sollten gerade die hier vorausgeschickten, scheinbar weit abschweifenden Exkurse einleuchtende Erklärungen bieten, und so kann nun ohne weiteren Kommentar Forster selbst zu Worte kommen, beginnend an dem Punkt, wo sich seine Vorlesung grundsätzlich von Blumenbachs Abhandlung entfernt:

Nun glaube ich, die Frage nach dem Unterschied zwischen den Menschen und den übrigen Tieren zur Genüge beantwortet zu haben. Die andere Frage ist, ob die Menschengattung (genus humanum) aus mehreren Arten (pluribus speciebus) besteht oder ob es nur eine Art ist, die diese Gattung bildet.

Wenn wir uns nicht um des Kaisers Bart streiten wollen, müssen wir von einer Definition ausgehen. Es ist nämlich offensichtlich, daß in den verschiedenen Weltteilen vielfältige Exempla von Menschen zu finden sind, und deshalb bietet sich uns ein weiter Bereich, in dem man verschiedener Meinung sein kann, je nachdem, welchen Begriff man sich davon gebildet hat, was eine Art und was eine Gattung ausmacht.

Einige definieren eine Art so, daß sie behaupten, alle Tiere, die von einem einzigen Tierpaar abstammen, bilden eine Art. Dies wäre die beste Definition, wenn sie zu beweisen wäre. Aber ich frage, auf welchen Grund man sich stützen kann, um zu wissen, ob z. B. alle die zahlreichen Hunderassen von einem einzigen Paar abstammen? Wer bietet uns einen glaubwürdigen historischen Bericht, sei er geschrieben oder durch Tradition überliefert, mit dem, ich will gar nicht sagen nachgewiesen, aber wenigstens wahrscheinlich gemacht wird, daß die Individuen einer jeden Art von einem einzigen Paar abstammen? Dies gibt es nicht und kann es nicht geben. Das Zahlenverhältnis zwischen den Tieren können wir uns gar nicht anders vorstellen, als es jetzt besteht. Gesetzt, es habe am Anfang nur ein einziges Paar von Löwen, Tigern, Panthern, Luchsen, Bären, Wölfen, Hyänen und anderen fleischfressenden Tieren gegeben, dies wenigstens mag sich nicht widersprechen. Aber da sich nun die Löwen, Tiger, Panther und anderen fleischfressenden Arten von den wehrlosen und schwächeren pflanzenfressenden Arten ernähren, wie etwa Schafen, Ziegen, Hasen, Antilopen, Hirschen und anderen dergleichen, sieht man da nicht ein, daß diese schon bei ihrem ersten Auftreten auf der Stelle ausgerottet worden wären, wenn man annähme, daß von diesen Tieren ebenfalls nur ein Paar vorhanden gewesen sei? Ein Löwe hätte eine ganze Art oder sogar mehrere

152 Forster greift hier auf eine Argumentationskette zurück, die er bereits in den methodischen Vorüberlegungen der Vorlesung vorbringt (AA VI 1570f.). 
vernichtet, wenn er nur einmal und zum ersten Mal seinen Magen gefüllt hätte. Deshalb ist es höchst wahrscheinlich, daß wenigstens einige Arten, wenn nicht alle, auch von mehreren Paaren am Anfang der Welt abstammen. Da jene Regel nicht für alle Arten zutrifft, kann sie nicht zu einer allgemeinen Definition dienen.

Es ist also nötig, seine Zuflucht bei einer anderen Definition einer Art $\mathrm{zu}$ suchen, die stimmiger ist und für alle Arten zutrifft. Diese Definition rühmen sich diejenigen gefunden zu haben, die überzeugt sind, das Ganze beruhe völlig auf der fruchtbaren Paarung der Tiere.

Nach ihrer Meinung nämlich gehören diejenigen Tiere zur selben Art, aus deren Vermischung vollkommen ausgebildete Sprößlinge hervorgehen. [am Rand:] (Corp. Org. 37.d.) ${ }^{153}$ „Aber wir wissen, daß ein Esel mit einer Pferdestute einen Maulesel und ein Pferdehengst mit einer Eselin ein Maultier erzeugen. Danach würden Esel und Pferd nur eine Art darstellen, obwohl sie sich doch durch offensichtliche charakteristische Kennzeichen voneinander unterscheiden." Darauf antworten die Gegner, es sei nicht genug, wenn aus der Paarung verschiedener Individuen Nachkommen entspringen, es sei nötig, daß diese fruchtbar sind, um ihre Art fortpflanzen zu können; Maulesel und Maultiere seien aber unfruchtbar. „Ich würde schweigen, da es doch Beispiele gibt, wenn auch seltene, wo Mauleselinnen Junge haben. Tatsächlich scheint mir mehr gegen diese Definition zu sprechen, daß der Kanarienvogel mit dem Stieglitz, der doch ein ganz verschiedener Vogel ist, mit dem Fink, mit dem Hänfling und anderen eine fruchtbare Begattung ausübt, und daß auch die Mischlinge, die daraus hervorgehen, fruchtbare Nachkommen erzeugen können. Deshalb finde ich diese Fortpflanzungsregel unzulänglich zur korrekten Begründung einer Artdefiniton. Zur Zeugung von Nachkommen genügt es nämlich, daß die Genitalien beider Gatten zueinander passen und daß die Schwangerschaftsperioden der beiden Arten nicht allzu sehr verschieden sind, wenn auch in der übrigen Körpergestalt größere Unterschiede bestehen können. Es ist nicht durch genügend Experimente bewiesen, welche Tierarten sich durch fruchtbare Begattung untereinander fortpflanzen können und welche nicht.["] Schließlich könnte es zufällig eintreten, daß sogar eine Begattung zwischen Menschen und Affen fruchtbar ist, wenn ein derartiges Experiment auch schlechthin zu verabscheuen ist; sollen wir dann glauben, daß die Menschen mit den Affen bis zur Artgemeinschaft verbunden sind? Tatsächlich mißfällt mir diese ganze Art der Definition. Denn angenommen, wir hätten zwei verschiedene aber einander ähnliche Tiere, und es sei die Frage, ob sie zur selben Art oder zu zwei verschiedenen gehören. Wie

153 Dies verweist auf Charles Bonnet: Considérations sur les corps organisés, où l'on traite de leur origine, de leur développement, de leur réproduction, \&c. \& où l'on a rassemblé en abrégé tout ce que l'histoire naturelle offre de plus certain \& de plus intéressant sur ce sujet. Amsterdam: Ray 1762 u. weitere Auflagen, Neudruck [Paris]: Fayard 1985. Ich danke Klaus-Georg Popp für den Hinweis auf Bonnet. 
kann man die Sache mit Sicherheit entscheiden? Sie müssen sich paaren. Aber zufällig sind sie nicht verschiedenen Geschlechts, beides sind Männchen oder Weibchen. Immerhin will ich dir zu Gefallen zugestehen, daß eines ein Männchen ist und das andere ein Weibchen; sie mögen sich paaren, und sogar ein Junges soll geboren werden; dieses Junge soll heranwachsen und sich mit einem anderen dritten Tier paaren, das entweder aus der mütterlichen oder der väterlichen Art herbeizubringen ist, damit du schließlich erkennen kannst, ob es zur Fortpflanzung geeignet ist. Inzwischen sind vielleicht viele Jahre vergangen; der Beobachter selbst ist gestorben oder anderswohin gezogen. Kurzum, ich glaube nicht, daß die Naturgeschichte vernünftigerweise so $\mathrm{zu}$ betreiben ist, daß ein Naturforscher viele Jahre dafür aufwenden muß, die Art von Tieren zu bestimmen. Vielmehr muß einem jeden Tier auf der Stelle, gleich nach dem ersten Anblick, in Anbetracht seiner natürlichen äußeren Kennzeichen sein Platz im künstlichen System zugeteilt werden. Was ist nun die wahre Definition einer Art? Ich jedenfalls kann keine andere angeben als die eine, die hier folgt:

Alle Individuen, die in Anzahl, Gestalt, Stellung und Proportion der äußeren Körperteile übereinstimmen, machen eine einzige Art aus; zu verschiedenen Arten gehören aber diejenigen, die sich in Anzahl, Gestalt, Stellung und Proportion der Körperteile voneinander unterscheiden. Hier muß keine Zuflucht bei Fortpflanzung und Abstammung gesucht werden, denn die Natur täuscht uns nicht, und aus Gleichem geht nichts Ungleiches hervor, sondern die Nachkommen sind immer den Eltern gleich.

Nun müssen wir uns nur noch auf die Definition einer Gattung (genus) besinnen: Eine Gattung in unserem Sinn faßt solche Arten, die ein gewisses einzelnes Kennzeichen besitzen, zu einer Gruppe zusammen. Es gibt aber Gattungen, die nur eine einzige Art umfassen; d.h. es gibt Tiere, die so vereinzelt gebildet sind, daß sie nicht mit anderen Tieren in eine Gattung zusammengezwängt werden können; daher sind sie gesondert in das System einzuordnen.

Um diese Definitionen auf den Menschen anzuwenden, fragen wir zuerst, ob sich bei ihm Charakteristika oder bestimmte körperliche Kennzeichen finden, die eine Trennung des Menschen von den Affen als einer besonderen Gattung (genus) erlauben. Linnè, gewiß die große Autorität in der Naturgeschichte, war darüber im Zweifel und gestand,

1) er habe noch keine solchen Kennzeichen gefunden, die den Menschen als eine Gattung von den Affen unterschieden. Dennoch hat er selbst diese Unterscheidung getroffen, damit man ihm nicht vorwerfen könnte, widersinnig zu sein. Diese Richtung schlagen auch wir am liebsten ein. Denn sonst genügen die Merkmale, die den Menschen von den Affen unterscheiden, sicher zur Bestimmung einer Art (species), aber nicht einer Gattung. Die Zahl der Zähne ist nämlich dieselbe, auch ihre Stellung ist ungefähr gleich; die Zahl der Finger ist gleich, der Daumen ist genau so abgesetzt; die Brustwarzen sind ähnlich in der Brust gelagert, der übrige Körper stimmt außerordentlich überein. Dagegen vermögen der Gang auf 
zwei Beinen, die abstehende Richtung der Fußsohlen, das Fehlen des Zwischenkieferknochens und so weiter wohl eine Art zu bestimmen, nicht aber eine besondere Gattung aufzustellen. Trotzdem, mag uns auch unsere Verwandtschaft mit den häßlichsten Tieren immer an unsere Eitelkeit erinnern und dazu dienen, Hochmut und Anmaßung der Menschen niederzuhalten, so wollen wir dennoch, um nicht unseren Vorrang zu vergessen, der im Gebrauch der Vernunft besteht, den Menschen für sich in eine besondere Gattung (genus) setzen.

2) Die zweite Frage sollte leicht zu entscheiden sein: ob nur eine Menschenart anzunehmen ist oder mehrere. Ganz sicher kann man nämlich antworten, daß nach unserer Definition an allen Orten, wohin wir gelangt sind, keine anderen Menschen gefunden worden sind, als solche, die nach Zahl, Stellung, Gestalt und Proportion der Körperteile gleich sind, und daß daher alle in eine Art einzuordnen sind.

Trotzdem gibt es gewisse Unterschiede geringerer Art, nämlich in Farbe, Größe und Behaarung, ja auch geringfügige Verschiedenheiten in der Gestalt unter den Einwohnern der verschiedenen Erdteile, die ebensoviele fortdauernde Exempla von Menschen darstellen. Ich nenne sie Exempla, nicht etwa Varietäten (varietates), denn Varietäten sind nicht fest bleibend, sondern sie kehren zu den ursprünglich angeborenen Anlagen der Vorfahren zurück, von denen sie abstammen, und müssen für zufällig oder äußerlich gehalten werden. Das Merkmal der Exempla dagegen ist unauslöschlich, es bleibt immer in der Nachkommenschaft und ist ihr gleichsam eingebrannt bis auf die letzten Generationen. Der Unterschied zwischen den Varietäten und den Exempla liegt darin, daß wir bei den Varietäten wissen, welche Art sie ursprünglich gemeinsam hatten; den Ursprung der Exempla jedoch kennen wir schlechterdings nicht. Denn wer kann uns sagen, ob die Äthiopier, oder die Afrikaner vom Niger, d. h. jene schwarzen Menschen mit plattgedrückter Nase, geschwollenen Lippen und wolligem krausem Haar, mit uns einen gemeinsamen Ursprung haben oder nicht? Wer kann behaupten, ob die Völker Amerikas dieselbe Abstammung haben wie die Europäer und Asiaten, oder ob sie eine getrennte Herkunft haben? Ich jedenfalls habe, so viele Bücher ich bisher nachschlagen konnte, bei keinem Autor einen solchen Beweis gefunden, und ich gestehe, daß ich nur immer unsicherer geworden bin als vorher. Deshalb werde ich zunächst die wohlgeordnete und vorzügliche Beschreibung der menschlichen Art vortragen, die Linné mit männlicher Hand gezeichnet hat, und dann die Exempla aufzählen, die bisher auf dem Erdkreis gefunden worden sind.

Es folgt die Beschreibung Linnés. ${ }^{154}$

Dieser letzte Satz gibt wahrscheinlich dem dozierenden Forster selbst das Stichwort dafür, an dieser Stelle den von ihm verbesserten Linnéschen Text aus seinem Kompendium vorzutragen.

154 Übersetzt aus dem Lateinischen in AA VI 1670-1673. 
Nach dieser allgemeinen Bestimmung der menschlichen Art behandelt Forster die „Exempla und Varietäten, die in der menschlichen Art beobachtet worden sind“. ${ }^{155}$ Zunächst bietet er lange Aufzählungen von Extrem- und Sonderformen, wie Riesen und Zwergen, Hautverfärbungen, Mißbildungen, künstlichen Verunstaltungen, verwilderten Kindern und fälschlich als Abartungen ausgegebenen Erkrankungen, darunter kuriosen Einzelfällen und Fabelwesen aus kolportagehaften Schilderungen der historischen Überlieferung. Neben anderen Quellen folgt Forster auch hier hauptsächlich Blumenbach. Wie dieser zählt Forster alle auffindbaren Fälle auf und entlarvt mit nüchterner Kritik viele als Übertreibungen und phantastische Fabeln. So rekapituliert er seine eigene Kasseler Rede über die Pygmäen mit ihrer rein allegorischen Deutung dieser aus der antiken Literatur bekannten Zwerge. ${ }^{156}$ Forsters eigener Sinn für Sprache und seine polyglotte Sprachfähigkeit bezeugen sich darin, daß er unter den Varietäten auch die Verschiedenheit der Sprachen und die phonetischen Beschränkungen bestimmter Nationalsprachen bedenkt und $\mathrm{zu}$ begründen sucht. ${ }^{157}$ So weit es bei der bunten Sammlung oft fragwürdiger Zeugnisse auszumachen ist, handelt es sich dabei hauptsächlich, nach Forsters Definition, um Varietäten. ${ }^{158}$ Wenn er hier gelegentlich das Wort „exemplum“ benutzt, so bezeichnet er damit, dem üblichen Sprachgebrauch folgend, rein individuelle Einzelfälle. ${ }^{159}$

155 „Exempla et Varietates in Specie Humana observatae“ AA VI 1674.

156 AA VI 1675f., vgl. VIII 108-121 und Uhlig 2004 S. 132.

157 „Loquelae maximae sunt diversitates in hominum variis gentibus, quae neutiquam omnes a Climatis, coelive potentia derivari possunt; licet verum sit in genere, gutturalem esse pronunciationem monticularum, diducto autem ore et in longum tractis vocabulis maritimos populos loqui. Caeterum, dissimillimo sermone saepius gaudent populi vicini, quibus eadem coeli temperies est, et fere vitae genus idem. Singulares autem defectus nonnulli observantur in loquela diversorum populorum quorum caussa nondum satis in aperto est. Cur enim Hispani litteram $m$ finalem pronunciare nesciunt? Sinenses $r$ et $d$ proferre non possunt. Groenlandiis molestum est $x$ et $t s c h$ enunciare. Taheitenses $s$ litteram et omne sibilum pronunciare non valent; neque Vocem proferunt, cuius non omnes syllabae in vocales exeant?" AA VI 1682.

$158 \mathrm{Im}$ Kompendium wird dieser Abschnitt folgendermaßen zusammengefaßt: „Varietates speciei humanae plures, loco, victû, Exemplorum commixtione, cultura, arte diversae." AA VI 1507.

159 Zum Beispiel: „Sed eiusmodi exempla solitaria sunt et infrequentia,“ AA VI 1674, ,6..$^{\circ}$ artificialium diversitatum exempla.“ AA VI 1682, „Hominum nonnulla exstant exempla, miserorum, qui inter feras expositi vel casu oberrantes, harum forte pietate enutriti sunt et educati.“ AA VI 1685, „Recentioris aevi exempla e diversissimis et maxime dissitis orbis nostri partibus vidimus. Ex Germania cel. 
Die nächsten zwei Abschnitte dagegen beziehen sich auf Exempla genau und ausschließlich in dem terminologischen Sinne der Definition in dem Kompendium. Unter dem Titel: Hauptsächliche Exempla in der einen Menschenart ${ }^{160}$ begründet Forster seine Einteilung der Menschenrassen folgendermaßen:

Da heutzutage fast alle Regionen des ganzen Erdkreises von Menschen besiedelt sind, da diese sich durch Handel, Schifffahrt, Krieg und viele andere Ereignisse miteinander vermischen, scheint es völlig unmöglich zu sein, den Übergang von einer Menschenform in eine andere zu beobachten, und es ist schon an sich offenbar, daß keine festen und bestimmten Grenzen zwischen ihnen bestehen. Es kann auch gar nicht anders sein, da doch die meisten Einteilungen der menschlichen Gattung in bestimmte Varietäten, die wiederholt von berühmten Männern versucht worden sind, sich nur als höchst willkürlich und unbestimmt erweisen mußten. Zweifellos könnten wir, wenn ältere Zeugnisse über die verschiedenen menschlichen Exempla existierten, darauf gestützt deren ursprüngliche Anzahl vollständiger und besser erforschen. Tatsächlich haben in den Urzeiten fast alle Völker gleichsam abgesondert und beinahe vom ganzen Erdkreis voneinander getrennt gelebt. Der Antike ganz und gar unbekannt erstreckte sich mehr als die Hälfte der ganzen Erde, obwohl sie doch ihre eigenen Einwohner hatte; die Römer nämlich hatten vom chinesischen Reich, von Japan, von ganz Sibirien und ganz Amerika nicht die geringste Kenntnis, und die Autoren dieser Zeit haben ihre Aufmerksamkeit nicht sorgfailtig genug auf die Dinge gerichtet, die am meisten zur Bestimmung der Unterschiede zwischen den Exempla beitragen.

Daher bleiben uns nur Vermutungen, wenn wir über die ursprünglichen Verschiedenheiten urteilen wollen. Wenn wir uns aber nicht auf Hypothesen verlassen wollen, müssen wir die heute bekannten Exempla aufzählen, so weit sie erkennbar sind, und dabei auch die offensichtlicheren Verschiedenheiten ihrer Gestalt und ihre eigentümlichen und charakteristischen Kennzeichen. Diese Regel habe ich mir bei der folgenden Aufzählung von Exempla vorgeschrieben, und ich habe mich vor allem bemüht, jeweils einen gewissen Punkt auf dem Erdkreis anzunehmen, wo die Menschenform insgesamt möglichst unverkennbar von den übrigen Exempeln abweicht; jeden einzelnen dieser Punkte nehme ich gleichsam als Zentrum eines einzelnen Exempels an; aber die Peripherie des Kreises, den diese oder jene Menschengruppe einnimmt, habe ich nicht immer zu umschreiben gewagt, da ich sehr wohl erkennen muß, daß diese Peripherien einan-

Blumenbach exemplum iuvenis cuiusdam sibi amici adduxit, [...] in Malabarico regno exempla bene multa exstant." AA VI 1691; in einem Fall wird die Klassifizierung als Exemplum ausdrücklich abgelehnt: „de morbis perperam inter Exempla humanae speciei recensitis." AA VI 1687.

160 „Exempla praecipua in Hominis Specie unica“ AA VI 1692. 
der überschneiden und gerade in den Überschneidungen unvermeidliche Mischungen unter den Exempeln entstehen.

Ich nehme sieben Punkte dieser Art an: 1) in Nordamerika jenseits des 60. nördlichen Breitengrads, 2) in Amerika um die nördlichen Teile des Königreichs Mexiko, 3) im Altaigebirge von Asien, 4) in Indien am Ganges, 5) im Kaukasusgebirge, 6) in Guinea in Afrika, 7) in den ostindischen Inseln von Neuguinea. ${ }^{161}$

Darauf teilt Forster die Art „Homo (Sapiens) erectus“ insgesamt in die folgenden sieben „Exempla Hominum“, d. h. also Rassen, ein: 1. die Grönländer und Eskimos, 2. die amerikanischen Indianer, 3. die Skythen, Mongolen, Kalmücken und Chinesen, 4. die Inder, zu denen er auch die alten Ägypter zählt, ${ }^{162} 5$. die Kaukasier, 6. die Afrikaner und 7. die Australier. ${ }^{163}$ Die ausführlichen Beschreibungen der einzelnen Rassen enthalten sowohl physische Charakterisierungen wie Bemerkungen zur Lebenskultur, in denen sich neben eigenen Erfahrungen Forsters auch viele seinerzeit geläufige Vorurteile niederschlagen. Forster weist nicht ganz von der Hand, daß es weitere Rassen geben könne; andererseits gibt er die Möglichkeit zu, daß einige der von ihm als gesondert bezeichneten Rassen durch den Beweis eines gemeinsamen Ursprungs miteinander $\mathrm{zu}$ vereinigen sind. So lasse sich etwa eine größere Ähnlichkeit und damit Verwandtschaft zwischen den amerikanischen und den altaischen Völkern erweisen, und die Kaukasier könnten mit den Indern verbunden werden. Zur Verdeutlichung seiner Unterscheidung der Begriffe „Varietät“ und „Exemplum“ weist Forster darauf hin, daß innerhalb der so bestimmten Exempla alle möglichen Varietäten auftreten können. ${ }^{164}$

Diese Aufstellung ist wesentlich differenzierter als die damals gängigen Rasseneinteilungen von Linné, Buffon, Kant und Blumenbach. Am nächsten stehen ihr die Beschreibungen, die Herder im 6. Buch seiner Ideen zur Philosophie der Geschichte der Menschheit bietet, wo allerdings

161 Übersetzt aus dem Lateinischen in AA VI 1692.

162 „Equidem Aegyptiorum populum, cui antiquitus [im Druck: antiquitas] non solum Mores, verum et corporis notae hodiernis Indis simillimae competebant, ad hocce hominum exemplar accensendum esse nullus dubito." AA VI 1697. Im dritten Teil seiner Ideen bemerkte 1787 auch Herder, die Ägypter seien „,wahrscheinlich ein Südasiatisches Volk, das Westwärts über das rote Meer oder gar weiterhin herkam und sich von Aethiopien aus allmählich über Aegypten verbreitete." (Herder Bd VI S. 501).

163 „,(Arcticus) Groenlandius“ AA VI 1693f., „Americanus“ AA VI 1694f., „(Scytha.) Mogolus (Kalmyccus) Sinensis“ AA VI 1695f., „Indus“ AAVI 1696f., „Caucasius“ AA VI 1697f., ,,afer" AA VI 1698f., ,australis“ AA VI $1699 \mathrm{f}$.

164 AA VI $1700 f$. 
nicht distinkt getrennte Rassen bezeichnet werden, sondern vielmehr „ein fortgehendes Gemälde klimatischer Nationalbildungen“ geliefert wird. ${ }^{165}$ Blumenbach hatte in seiner Dissertation ursprünglich vier Rassen angenommen. In der zweiten Fassung dieses Werks, die Forsters Vorlesung zugrundelag, hatte er einer fünften Rasse den Pazifik, einschließlich der Sunda-Inseln, Molukken und Philippinen, eingeräumt, wozu ihn J. R. Forsters Observations angeregt hatten. ${ }^{166}$ Dort waren freilich, wie hier bereits bemerkt, die Bewohner dieses Gebiets als Einwanderer aus zwei verschiedenen Herkunftsbereichen bezeichnet worden. Dem entspricht Georg Forsters Vorlesung insofern, als sie die Polynesier nicht eigens erwähnt, sondern implizit der über China hinaus nach Süden hin ausgebreiteten mongolischen Rasse zuordnet, ${ }^{167}$ während sie die Melanesier zum „homo australis“ zählt, dessen Zentralpunkt sie auf Neuguinea ansetzt. ${ }^{168}$ In seiner Lobschrift auf Cook führt Forster unter den thesenhaften Resultaten der Reisen Cooks die beiden Südseerassen an, ohne auf deren Herkunft einzugehen. ${ }^{169}$

Indem Forster auch bei der Definition eines Exemplum, d. h. nach seiner Bestimmung: einer Rasse, betont von der Frage der Herkunft absah und sich auf die deskriptive Morphologie beschränkte, nahm er

165 Herder Bd VI S. 209-250, Zitat S. 390.

166 ,QVINTAM [scil. varietatem] demum constituit nouus orbis australis, cui ni fallor quoque insulae Sundaicae, Moluccae, Philippinae etc. commode accenseri possent, hominibus in vniversum coloris intense fusci, naso lato, et denso capillo. Illos qui archipelagum pacificum inhabitant Cel. IO. REINH. FORSTER iterum in binas diuidit Tribus. Altera quam Utahittenses, Nouozeelandi et incolae insularum amicarum (Friendly Isles), Societatis, Paschatis, Marquesas etc. constituunt, homines elegantioris figurae et placidi magis ingenii complectitur: cum reliqui qui nempe nouam Caledoniam, Tannam, Nouas Hebrides etc. incolunt, magis nigri, crispi, et quod ad ingenium magis diffidentes et feroces sint." Blumenbach 1781. S. 52. Eine Anmerkung verweist auf J. R. Forsters Observations.

167 „Tertium humanae formae exemplum in Altaico monte Asiae reperio, atque huc refero Mogolicas, ut vocantur, Gentes, immo Kalmyccos, Tibetanos, Koreanos, Japonenses et Sinenses, nec non in universum Sibiriae plurimas gentes, multasque alias, quae a Sinae imperio versus austrum inhabitant." AA VI 1695.

168 „Ii Novam Hollandiam, vastissimam terram, quae Europae superficiem exaequare Videtur, tum proxime adjacentem Novam Guineam, nec non aliquot insulas oceani pacifici, orientem versus positas, et alias in Moluccarum, et Philippinarum Archipelago, inhabitant. Princeps tamen eorum Sedes in Nova Guinea videtur positas [im Druck: posita] esse, quamquam et in N. Hollandia, absque omni commixtura cum aliis hominum exemplaribus reperiantur." AA VI $1699 f$.

169 AA V 280. 
ausdrücklich den Vorschlag einer polyphyletischen Abstammung zurück, den er in seinem Essay über die Menschenrassen vorgebracht hatte. Andererseits beließ er damit den Rassen immer noch eine stärker ausgeprägte eigenständige Identität, als wenn er ihre Existenz kurzerhand, wie seinerzeit üblich (und logisch fast unumgänglich), durch eine Degeneration von einem gemeinsamen Stamm erklärt hätte. Dies ist nur das früheste von weiteren Zeugnissen dafür, daß er sich nun mit skeptischem Agnostizismus bei der Frage der menschlichen Herkunft ausdrücklich seiner Stimme enthielt. So schrieb er am 21. Januar 1787 an Herder, er sei weit entfernt,

zu glauben, daß das Menschengeschlecht wirklich mehrere Stammväter gehabt habe, sei erwiesen. Ich denke nur, die Sache hat gewonnen, daß man sie einmal von einer andern Seite ansieht, und daß man zeigt, wie wenig die bisherigen Beweise das leisteten, was man von ihnen behauptete. ${ }^{170}$

Ein undatiertes Fragment, das unter dem Titel Menschen-Racen überliefert ist, rekapituliert den Standpunkt der Vorlesung von 1786/87, indem es erklärt, daß „die Menschen Einer Gattung sind, ist wohl ausgemacht, sobald man den Begrif von Gattung so bestimmt, daß es sich ausmachen läßt," und daran die skeptische Einschränkung anschließt:

$\mathrm{Ob}$ sie aber alle Eines Stammes sind, folgt daraus noch lange nicht; im Gegentheil, soweit ich jezt zu beurtheilen im Stande bin, wird dies immer Glaubenssache bleiben, d. i. eine Sache, wovon man höchstens nur Muthmaßungen haben, und eine der andern vorziehen kann. ${ }^{171}$

In seiner Liste der Resultate von Cooks Reisen behauptet Forster,

$\mathrm{da} \beta$ die Natur des Menschen zwar überall klimatisch verschieden, aber im Ganzen, sowohl der Organisation nach, als in Beziehung auf die Triebe und den Gang ihrer Entwickelung, specifisch dieselbe ist. ${ }^{172}$

Das Wort „specifisch“ deutet auf den naturhistorischen Begriff der Species, deren Einheit hier betont wird, ohne daß von der Abstammung die Rede wäre.

Als Forster 1789 die gewichtigsten seiner früheren Kleinen Schriften in einem Sammelband erneut herausgab, schloß er davon den Artikel Noch etwas über die Menschenraßen aus, ohne ihn überhaupt zu erwähnen. ${ }^{173}$ Dies fällt um so mehr auf, als Forster in der Vorrede zu diesem

170 AA XIV 621.

171 AA VIII 157.

172 AA V 280.

173 Kleine Schriften. Ein Beytrag zur Völker- und Länderkunde, Naturgeschichte und Philosophie des Lebens, gesammlet von Georg Forster. Erster Theil. Leip- 
Band, wie oben bereits bemerkt, ausdrücklich die Anthropologie zum Zentralthema seiner bisherigen Forschungen erklärt und einleitend die fünf abgedruckten Arbeiten mit ihren jeweiligen Anlässen in ihrer chronologischen Reihenfolge vorstellt, die von 1780 bis 1789 reicht. Hier hätte auch der Menschenrassen-Artikel seinen angemessenen Platz gehabt, den Forster polemisch erregt und mit provozierendem Nachdruck im Sommer 1786 verfaßt hatte. Wenn er diese Schrift nun jedoch mit völligem Stillschweigen übergeht und damit eine spürbare Lücke in der Dokumentation seines Werks zuläßt, so kann dies nur bedeuten, daß Forster sich mit Absicht davon distanziert. Die zoologische Vorlesung ist freilich in dem Band auch nicht vertreten. Mit ihrer akademischen Form, zumal ihrer lateinischen Sprache, paßte sie nicht in eine Sammlung kleiner deutscher Schriften, die alle bereits anderwärts publiziert waren. Aber mit ihr hatte Forster doch den Artikel über die Menschenrassen weit hinter sich gelassen, und von dem höheren Standpunkt aus, den er damit erreicht hatte, mochte er sich wohl nicht noch einmal mit einem autorisierten Neudruck zu dieser überholten Äußerung bekennen. In diesem Sinn änderte er auch in dem Sammelband bei der Schrift über den Brotbaum einen Passus derart, daß die Afrikaner nicht mehr mit selbstverständlicher Überzeugung als „unsere Brüder“ bezeichnet werden, sondern zurückhaltend als vernunftbegabte Menschen, „ihr Abstamm sey so ungewis wie man will“". ${ }^{174}$ Vielleicht war Forster auch tatsächlich mit dem „Anstrich von polemisierender übler Laune“ des Artikels über die Menschenrassen unzufrieden, wie er im Herbst 1790 an Kant ausrichten ließ, als er respektvolle Grüße mit diesem tauschte und sich für die polemische Schärfe seines Angriffs entschuldigte, die er auf seine damalige körperliche Indisposition zurückführte. ${ }^{175}$ Es ist sehr gut möglich, daß Forster später dazu ansetzte, den Artikel nachträglich umzuarbeiten; das oben erwähnte Fragment Menschen-Racen könnte als Teil einer geplanten Neufassung entstanden sein. Diese Vermutung legt eine Bemerkung L. F. Hubers nahe, der, wohl ohne genaue Kenntnis

zig: Kummer 1789. Der Band enthält Forsters Vorrede, datiert „Mainz den 31. März, 1789." (7 unpag. S.), sowie (ausdrücklich nicht chronologisch angeordnet): Cook, der Entdecker (S. 1-232), Neuholland und die brittische Colonie in Botany-Bay (S. 233-274), O-Taheiti (S. 275-354), Ueber Leckereyen (S. 355-392) und Der Brodbaum (S. 393-464). Vgl. Uhlig 2004 S. 243.

174 Georg Forster: Vom Brodbaum. [Cassel]: 1784. S. 3, vgl. dagegen AA VI 64.

175 AA XVI 185, 459f. Ohne Begründung oder Beweis behauptet Siegfried Scheibe, der Herausgeber des Artikels in der Akademie-Ausgabe, Forster gebe hier „nicht die wirkliche Einschätzung seines Aufsatzes über die 'Menschenraßen'“ wieder (AA VIII 407f.). 
der Zusammenhänge, den Artikel in den von ihm posthum herausgegebenen zweiten Band der Kleinen Schriften Forsters aufnahm. ${ }^{176}$

1791 mokierte sich Forster noch einmal, diesmal jedoch vom Standpunkt der prinzipiellen Skepsis aus, über den Versuch, den biblischen Adam zum Stammvater der amerikanischen Indianer zu machen,

Adam, das Geschöpf irgend einer Orientalischen Phantasie, die sich zur Erklärung des Überganges aus dem Unbegreiflichen ins Begreifliche, so gut wie jeder andere endliche Geist, eine Hypothese schaffen mußte.

Dies trug ihm die indignierte Denunziation eines Mainzer Klerikers ein. ${ }^{177}$ Die Fragen der Schöpfung und Abstammung ließ Forster auch beiseite, als er, von Herder angeregt, in dem Essay Über lokale und allgemeine Bildung ein anderes „Gesetz der Mannichfaltigkeit" für die Differenzierung der „lokalen Bildungen“ entwarf: diese bieten jeweils eine Auswahl aus den Zügen, die allesamt im Prototyp des Menschen angelegt sind, aber nur distributiv gesondert, auf die einzelnen Volkscharaktere auseinandergefächert, tatsächlich zur Entwicklung kommen. ${ }^{178}$

Nach dieser Abschweifung ist nun zum weiteren Verlauf von Forsters Vorlesung von 1786 zurückzukehren, wo eine „kurze Darstellung des physischen Lebens des Menschen“ geboten wird. ${ }^{179}$ Gestützt auf die medizinische Fachliteratur (er nennt einige Autoren, darunter Albrecht von Haller), verfolgt Forster den Lebenslauf eines Individuums durch alle Stadien der Entwicklung mit eingehenden anatomischen und physiologischen Beschreibungen. Einsetzend mit der Zeugung, verfolgt er das embryonale Wachstum bis zur Geburt, die weitere Entwicklung vom Säuglingsalter zur Entwöhnung und dem Zahnen bis zur Pubertät und dem Ende des Wachstums, das mit der Verhärtung der Knochen zu-

176 Georg Forster: Kleine Schriften. Ein Beytrag zur Völker- und Länderkunde, Naturgeschichte und Philosophie des Lebens. Zweyter Theil. Berlin: Voß 1794. S. 287-346. Huber leitete den Band mit der Bemerkung ein, Forster habe die Absicht gehabt, ,einen Theil seiner ältern wissenschaftlichen Abhandlungen mit wesentlichen Veränderungen dieser Sammlung einzuverleiben; aber seine Vorarbeiten dazu sind noch zu unförmlich, als daß ein andrer als er, sie hätte brauchen können; und es wird ohne Zweifel mehreren Lesern angenehm seyn, einige von diesen Aufsätzen, auch in ihrer unveränderten Gestalt, hier wieder zu finden“ (unpag. „Vorrede des Herausgebers“). So ging der Artikel auch unverändert in Forsters Sämmtliche Schriften (Leipzig: Brockhaus 1843. Bd 4. S. 280-306) und von da in die späteren Forster-Editionen über.

177 AA V 569f., 671-674.

178 Vgl. Ludwig Uhlig: Über lokale und allgemeine Bildung. Georg Forsters abschließender Beitrag zur Anthropologie. In: Herder Jahrbuch/Herder Yearbook. IX/2008. Heidelberg: Synchron Verl. 2008. S. 109-130.

179 „Vita Hominis physica breviter adumbrata“ AA VI 1701-1706. 
sammenfällt. Die besondere Aufmerksamkeit, die Forster dem Embryo und dem Säugling widmet, hat ihren Grund wahrscheinlich in einer persönlichen Erfahrung: kurz vorher war seine erste Tochter Therese geboren worden, an deren Entwicklung er liebevollen Anteil nahm. Wie seine Frau gegen die Landessitte darauf bestand, ihr Kind selbst zu stillen, so rät er in seiner Vorlesung dringend davon ab, eine Amme zuzuziehen, die schon einige Monate gesäugt hat, da deren Milch durch ihren übermäßigen Fettgehalt den Magen des Säuglings schwäche. ${ }^{180}$

Der Lebenslauf wird geschildert als ein Aufstieg zur „Blüte der Jahre" (,flos aetatis“) und ein darauf folgender Abfall der körperlichen Kräfte; die einzelnen Geisteskräfte treten in bestimmten Stadien in den Vordergrund:

Das Menschenleben hat zwei Stufen, die erste ist das Wachstum, die zweite die Abnahme; in jener gedeiht das Gedächtnis, in dieser die Urteilskraft. $[\ldots]$

Die Geisteskräfte blühen in verschiedenen Lebensstadien. Das Gedächtnis hat die größte Fassungskraft zwischen dem 7. und dem 15. Jahr. Danach verhärtet sich die Gehirnmasse mehr, und je mehr sie erstarrt, umso mühsamer faßt sie die Sinneseindrücke auf. Dann entfaltet die Phantasie ihre größten Kräfte, vor allem in der Blüte der Jahre. Zuletzt aber gewinnt die Urteilskraft die Oberhand, nachdem die Abnahme eingesetzt hat. Diese Wechselfälle beschreibt Haller schön. [...]

Die Blüte der Jahre beginnt, sobald der Mensch seine richtige Größe erreicht hat, und dauert gewöhnlich vom 20. bis zum 40. Jahr. Dies ist der schönste und angenehmste Teil des Lebens, denn das Gedächtnis ist kaum geschwächt, aber die Phantasie steht in voller Kraft, und die Urteilskraft beginnt sich hervorzutun. ${ }^{181}$

Nach der männlichen Geschlechtsreife und dem Stimmwechsel wird, in der damaligen Ausdrucksweise, das „Schwächere Geschlecht“ („Sexus

180 „Hinc male neonatis consulunt, qui nutricem accergunt jam per aliquot menses lactantem. Nimia enim huius lacteis pinguedine stomachus infantis debilitatur, etc." AA VI 1703; vgl. Uhlig 2004 S. 201.

181 „Vitae humanae duo sunt gradus, prior incrementi, alter decrementi; illo memoria viget, hoc autem judicium.“ AA VI 1702; „Animi vires variis vitae stadiis vigent. Memoriae maxima facilitas inter annum $7 \mathrm{mum}$ et $15 \mathrm{tum}$. Deinde Cerebri massa magis induratur, quae magis rigens, impressiones sensitivas aegrius accipit. Tum Phantasia suos vires maximas exserit, praeprimis in flore aetatis. Iudicium [im Druck: Indicium] tandem ultimo succedit, postquam incepit decrementum. Has vicissitudines pulchre depinxit Hallerus." AA VI 1703; „Flos aetatis incipit, quum justam longitudinem homo nactus sit, et ab anno 20 ad 40 perdurare solet. Pulcherrima ea est vitae portio, ac jucundissima, nam Memoria parum debilitata est, Phantasia autem viget, et Judicium incipit se exserere." AA VI 1703. 
sequior"), also das weibliche Geschlecht mit seiner Körperstruktur und seinen Geschlechtseigenheiten bedacht. Für die Eheschließung wird ein mittleres Alter empfohlen, die Geburtenstatistik lege in Europa die Monogamie nahe, in Afrika und Indien dagegen die Polygamie, die in der Türkei allerdings eine Folge sozialer Ungleichheit sei.

Ein beständiger Verschleiß zehre den Körper allmählich aus, dem wirke zunächst die Regeneration durch die Nahrung entgegen; aber die Versteifung der Glieder und Gelenke, Runzeln und die Abstumpfung von Phantasie, Gedächtnis und Sinnen bezeichneten den abschüssigen Weg zur Abnahme, die im Greisenalter zu Ende gehe. Eine Verjüngung im Alter, die Bacon nicht für unmöglich hielt, sei kaum wahrscheinlich; das Greisenalter bringe höchstens die Schwäche der Kindheit zurück. Nach einem Blick auf die Statistik der Sterbefälle und einzelne erstaunlich langlebige Menschen beschreibt Forster den Vorgang des Sterbens mit klinischer Exaktheit. Beiläufig gibt er die Gesamtbevölkerung der Erde mit einer Milliarde an, wovon alljährlich 30 Millionen sterben, aber 36 Millionen neu geboren werden.

Bekanntlich nahm Forster später mit seinem Essay Leitfaden zu einer künftigen Geschichte der Menschheit das Thema des Lebenslaufs wieder auf und wiederholte dabei auch einige Einzelzüge in der physischen Entwicklung, die in der Vorlesung vorkamen, freilich mit Überformungen und Umdeutungen; vor allem werden den physischen Abläufen gewisse Zwecke unterstellt. Aber ein Vergleich der beiden Texte zeigt größere und wesentlichere Unterschiede. So wird die ursprüngliche Kontur des Lebenslaufs als einer auf- und absteigenden Entwicklung mit einem Höhepunkt in der Mitte von dem Essay zu einem Vierstufenschema verwandelt. Dies ergibt sich daraus, daß Forster nun, angeregt von Matthew Priors komischem Lehrgedicht Alma, or the Progress of the Mind, die Abfolge der Impulse von vier verschiedenen Organen zum gliedernden Prinzip des Lebenslaufs macht; im Hintergrund steht dabei die Konvention der traditionellen Lebensaltermetaphorik. Beides aber sind Strukturen, die von vornherein als bildhaft konzipiert und verstanden werden, und dem entspricht es, daß der Lebenslauf in dem Essay gar nicht der direkte Gegenstand der Rede ist, sondern nur zum Gleichnis für historische Abläufe dient. ${ }^{182}$

Schon dies impliziert, daß hier zwei prinzipiell verschiedene Textsorten vorliegen und daß der Essay in einer ganz anderen Redeweise gehalten ist als die Vorlesung. Diese spricht und argumentiert mit einem direkten und ernsthaften Sachbezug und beansprucht für ihre Aussagen wissenschaftliche Geltung. Der Essay dagegen gibt schon am Anfang zu,

182 Vgl. Uhlig 2004 S. $244 f$. 
daß er nur, einem augenblicklichen Einfall folgend, spielerisch einen geläufigen Tropus verwende:

Kaum hatte ich jenes Gedicht wieder gelesen, so reihte sich in meinem Kopf ein ganzes Sistem der sogenanten Geschichte der Menschheit daran. Das Bindungsglied war jener so bekante, als gemißbrauchte Vergleich der verschiedenen Lebensepochen des einzelnen Menschen mit den Stufen der Kultur bei ganzen Familien und Völkern. Ich weis wieviel ich wage, indem ich diese Ähnlichkeit des Allgemeinen mit dem Besondern wieder hervorsuche. ${ }^{183}$

Wenn er am Ende des Essays mit unverhohlener Ironie verspricht, das so begründete „Sistem“ weiter auszuarbeiten nach einer Methode, mit deren Beschreibung er die bedenkenlos voreingenommenen Kompilationen des Göttinger Historikers Christoph Meiners persifliert, entzieht Forster seinem ganzen Gedankenspiel vollends den Anspruch darauf, als wissenschaftliche Aussage ernst genommen zu werden:

Ich verspare die Ausführung meines Sistems für ein dickes Buch, wozu ein Ozean von Citaten in Bereitschaft liegt, der bei seiner Überschwemmung alle Einwürfe, wie unsichere Dämme zu durchbrechen und zu vertilgen droht. Mit Citaten kämpft man ja gegen Citaten, und wie die Erfahrung lehrt, auch nicht selten sehr glücklich gegen den Menschenverstand. ${ }^{184}$

In der wissenschaftlichen Redeweise genau so zu Hause wie in der phantasievollen und oft humoristischen Bildlichkeit seiner Essays, kennt Forster auch den Unterschied zwischen beiden Diskursarten und verwahrt sich heftig gegen ihre Vermischung:

Daß die Gleichnisse $\mathrm{h}$ i $\mathrm{n} \mathrm{k}$ e $\mathrm{n}$, hätte man nie bemerkt, wenn man nicht versucht hätte, sie g e h e n zu machen; das heißt, wenn man sie nicht aus ihrer natürlichen Lage gerissen und durch fortgesetztes Allegorisiren ihre wahre Bestimmung, als bloß erläuternde Bilder zu dienen, vereitelt hätte. Kein Mensch hat das Recht, mit einem Gleichnisse so widersinnig umzugehen, und ich darf hier wohl das meinige in Schutz nehmen. ${ }^{185}$

In der Vorlesung schließt sich an die Beschreibung des Lebenslaufs ein Überblick über die vielfältigen und oft absonderlichen Lebensweisen der über alle Bereiche der Welt verbreiteten Menschen: sie finden sich in den verschiedensten Weltteilen; außer dem Feuer sind ihnen alle Elemente zugänglich, sie dringen ins Erdinnere ein und tauchen unter

183 AA VIII 186.

184 AA VIII 192f.

185 AA X/1 595. Tanja van Hoorn verfällt in ihrer Interpretation des Leitfadens genau dem Irrtum, gegen den Forster sich hier verwahrt (van Hoorn 2004 S. 177-233). 
Wasser, neuerdings können sie sogar mit Ballons in die Luft steigen. Forster mustert ihre Wohnsitze und ihre Ernährung, wobei er neben den gewöhnlichen tierischen und pflanzlichen Nahrungsmitteln auch allerlei ungewöhnliche und ekelerregende Speisen und Rauschmittel aufzählt und erwähnt, daß er selbst auf Neuseeland einen Fall von Menschenfresserei bezeugt hat. Hier greift er zurück auf Einzelheiten aus seiner Vorlesung De hominis in omni climate vivendi facultate und zitiert fast wörtlich eine Seite aus seiner Dissertation De plantis esculentis insularum oceani australis über die Neuseeländer. ${ }^{186}$

Zum Abschluß überschaut Forster die Gesamtheit der Menschen auf deren verschiedenen Kulturstufen, die er nach den Vorstellungen der schottischen Kulturphilosophie faßt, wenn er etwa den Erwerb des Lebensunterhalts als bestimmende Grundlage der Gesellschaftsform bezeichnet ${ }^{187}$ und die Stellung der Frauen in der Gesellschaft als Indiz für deren Entwicklungsstufe wertet: ${ }^{188}$

Über die Unterschiede zwischen den verschiedenen Menschen läßt sich fast unendlich viel sagen. Einige Völker, denen Prometheus Herzen aus feinerem Ton gebildet hat ${ }^{189}$ überragen durch gewisse angeborene Vorzüge die übrigen; andere sind gleichsam wertlosere Wesen ohne jeglichen Sinn für das Rechte und Gute. Die Geisteskultur ist verschiedenartig und reicht über fast zahllose Zwischenschritte von der Barbarei und geradezu tierischer Wildheit bis zur höchsten europäischen Weisheit und Lebensart. So unterscheiden sich die Völker als Fischer, Jäger, Hirten und Ackerbauern voneinander. Es ist erstaunlich, wie die Menschen in der Kleidung voneinander abweichen; in dem einen Punkt kommen alle, auch die ärmlichsten und wildesten miteinander überein, daß sie Schmuckstücke brauchen, da ihnen die Gaben der Natur nicht genügen. Auch die nackten Völker, denen überhaupt keinerlei Kleidung bekannt ist, sammeln oder bereiten mit

186 Vgl. AA VI 1710 mit AA VI 99f.

187 Vgl. Adam Smith: Lectures on Jurisprudence. Ed. R. L. Meek, D. D. Raphael and P. G. Stein. Oxford: Clarendon Press (1978). S. 14; Adam Ferguson: Institutes of Moral Philosophy. 3rd ed. Edinburgh: Bell \& Creech; London: Cadell and Robinson 1785. S. 30-38.

188 Vgl. John Millar: The Origin of the Distinction of Ranks: or, An Inquiry into the Circumstances which Give Rise to Influence and Authority, in the Different Members of Society. ed. and with an Introduction by Aaron Garrett. Indianapolis: Liberty Fund (2006). S. 93-156: Rank and Condition of Women; Henry Home, Lord Kames: Sketches of the History of Man. Considerably Enlarged by the Last Additions and Corrections of the Author. Book 1. Progress of Men Independent of Society. Ed. and with an Introduction by James A. Harris. Indianapolis: Liberty Fund (2007). S. 259-305: Sketch VI. Progress of the Female Sex.

189 Forster zitiert hier Juvenal, Sat. 14, 34. 
eigener Hand doch allerlei Schmuckstücke, die sie am Körper befestigen oder auch in ihn einfügen, wie ich bei früheren Gelegenheiten ausführlich berichtet habe. Alle Barbaren benutzen häufig Öle oder Farben. Fast alle wenden besondere Sorgfalt auf die Haare.

Abgesehen von den Unterschieden in Nahrung und Kleidung, hängen die jeweiligen Stufen der verschiedenen Kulturen direkt zusammen mit der Stellung des schwachen Geschlechts und der Kindererziehung. Das nämlich ist allen Barbaren gemeinsam, daß sie wie Tyrannen gegen ihre armen und verachteten Frauen wüten, die Kinder aber frei herumlungern lassen, ohne jede Erziehung. ${ }^{190}$ Die Völker, die gewohnt sind, Herden zu halten und zu besorgen, werden von herkömmlichen Sitten beherrscht; die Völker aber, die Ackerbau treiben, haben Gesetze und Vorschriften und dauerhafte Ordnungen. $\mathrm{Zu}$ erwähnen sind ferner die mannigfaltigen Vergnügungen der Menschen, nebst ihren vielfach verschiedenen Geistesarten und äußeren Gestalten, sowie den Regierungsarten und vieles andere dergleichen, was alles seine Grundlage in den physischen Anlagen des Menschen zu haben scheint. Aber von diesem Punkt an wird alles Weitere vollständiger und besser von anderen Wissenschaften behandelt. ${ }^{191}$

Der letzte Satz weist voraus auf eine grundlegende Wende in Forsters eigener schriftstellerischer Laufbahn. Zwar ermutigte ihn die Arbeit an der Vorlesung dazu, in den Briefen dieser Zeit Entwürfe zu umfassenden Darstellungen der Naturgeschichte vorzulegen, ${ }^{192}$ aber diese blieben sämtlich in ihren Anfangsstadien stecken. Das gilt auch für die den Brüdern Humboldt zugedachten Vorlesungen über allgemeine Naturkenntnis von 1792, deren Entwurfskizzen noch einmal Stichworte aus der Anthropologie der Vorlesung von 1786/87 aufnehmen. ${ }^{193}$ Die auf diese folgenden veröffentlichten Schriften Forsters dagegen, seit dem Essay Cook der Entdecker, lassen die Naturgeschichte im Hintergrund, während sie Kultur, Geschichte und Politik, später auch Kunst und Dichtung ins Zentrum rücken.

Die Alltagspraxis der Vorlesung tritt in den letzten Sätzen dieses überlängten Paragraphen 50 hervor: da seinen Hörern an diesem Punkt ein völlig neues Thema bevorsteht (nämlich die Gattung der Affen), möchte Forster damit erst nach den Weihnachtsferien beginnen und die nächsten beiden Kollegstunden, am Mittwoch dem 20. und Donnerstag dem 21. Dezember 1786, dazu verwenden, sein Kompendium weiter zu diktieren. Er glaubt seine Studenten, die diese Zusammenfassung von

190 Drastisch demonstriert Forster solche Verhältnisse auf Neuseeland mit einer Episode in seiner Voyage Round the World (AA I 294); vgl. auch AA VI 100.

191 Übersetzt aus dem Lateinischen in AA VI 1711f.

192 AA XIV 593, 599-601.

193 AA VI 1757. 
Anfang an mitgeschrieben haben, nicht eigens ermahnen zu müssen, dieses Angebot wahrzunehmen,

da ihr ja selbst schon gut genug wißt, wie wichtig es für euch ist, einen Leitfaden der Vorlesungen zu haben, an den ihr die Einzelheiten anknüpfen könnt, von denen in den Vorträgen ausführlicher und weitläufiger die Rede ist. ${ }^{194}$

Man hätte gern erfahren, wer diese Studenten waren und wie sie Forsters Vorlesung aufnahmen, aber darüber sind wohl kaum noch Zeugnisse zugänglich.

Die Bezüge dieser „Naturgeschichte des Menschen“ erstrecken sich weithin in verschiedene Richtungen: zurück zu Forsters eigener Beschreibung der Weltreise und deren wissenschaftlicher Auswertung, zu dem Artikel über die Menschenrassen, in die Gedankenkreise seiner gelehrten Vorgänger und Zeitgenossen und schließlich voraus zu seinen eigenen späteren Essays. Umgekehrt erschließt sich die volle Bedeutung dieses für Forsters Anthropologie zentralen Texts erst einer umfassenden Umschau in diesem weitgespannten Horizont. Bei Forster, dessen Leben und Wirken leider nur selten in der ganzen Breite ihres Gesamtumfangs zur Kenntnis genommen werden und von dessen Werk zu oft nur isolierte Einzelstücke unter eine meist stark verzerrende Lupe genommen werden, ist immer wieder auf die Beachtung des hermeneutischen Zirkels zu dringen, der den Teil aus seiner Verankerung im Ganzen versteht und zugleich das Ganze als das Gefüge seiner Teile begreift. ${ }^{195}$

$194,,[\ldots]$ siquidem et ipsi probe novistis, quantum intersit vestra, ut filum lectionum habeatis, cui adnectere singula poteritis, quae in lectionibus uberius atque fusius dicuntur.“ AA VI 1712.

195 Während der Korrekturarbeiten erhielt ich Horst Dippels Artikel: „Revolutionäre Anthropologie? Oder der Versuch, Georg Forster neu zu lesen“ (Historische Zeitschrift 291, 2010, S. 23-40). Herr Dippel geht darin auf die vorliegende Abhandlung ein, deren Manuskript ich ihm auf seine Bitte überlassen hatte. Ich stelle es dem Leser anheim zu beurteilen, ob Dippels Bemerkungen (zumal in seiner Anmerkung 4) zutreffen oder nicht. Jedenfalls fühle ich mich durch seinen Artikel bestärkt in meinem eingangs ausgesprochenen Urteil über die neuerlichen Bemühungen um Forsters Anthropologie. 
